\title{
The reach of the capitalist state
}

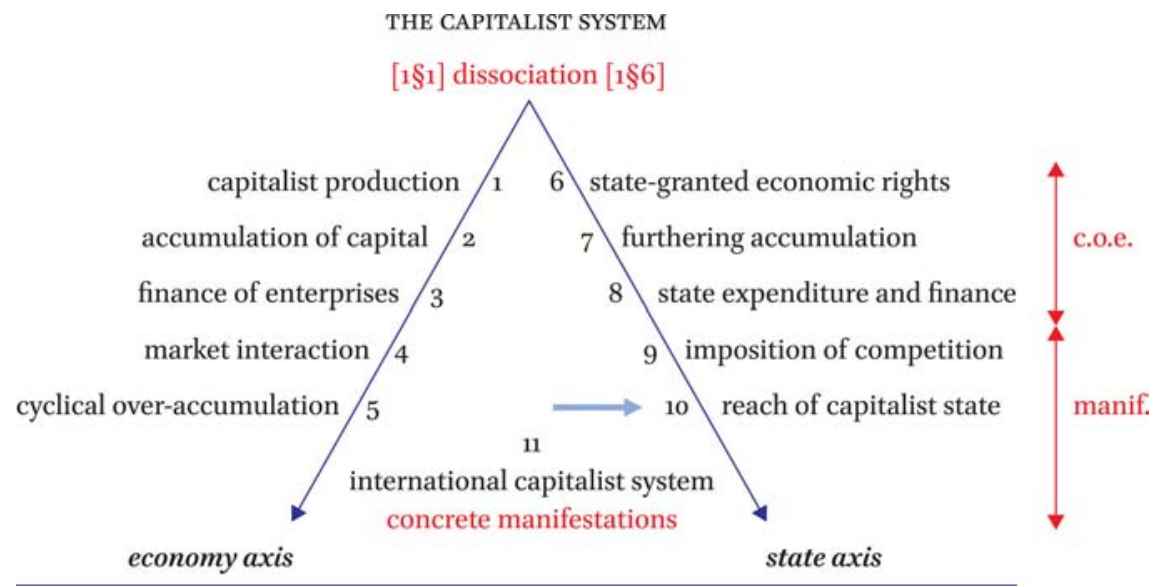

Note: 'c.o.e.' abbreviates conditions of existence and 'manif.' concrete manifestations.

\section{Contents}

Introduction $\quad 469$

Division 1. The size of state expenditure and its effect on the amplitude of the capitalist economic cycle 469

$10 \S 1$ The size of the state: state expenditure as mitigating economic recessions 469

$10 \S 2$ State policy in recessions versus depressions 475

Division 2. The increasing size and complexity of regulation 477

$10 \S 3$ Regulation: laws and delegated regulation 478

$10 \$ 4$ A conceptual outline of the reach of regulation 479

$10 \S 5$ Quantity and density of regulation: (too) simple measures 481

$10 \S 6$ Complexity of regulation: the combination of complication, interweaving and field fusion $\quad 487$

$10 \$ 7$ Change: the tendency to increasing complexity of regulation 490 
Division 3. The capitalist state's hard core and its manifestation in expenditure as quantitatively dominated by social security transfers 493

$1 \circ \S 8$ The manifestation of the state: the actors' experience of the state's existence 493

$10 \S 9$ The necessary state expenditure on the Hard Core and Inspectorates, and the contingent military and interest expenditure 495

$10 \S 10$ Expenditure on the monetary and labour-capacity frameworks 496

$10 \S 11$ Expenditure on the infrastructural framework 497

$10 \S 12$ Expenditure on social security as connected with the development of the accumulation of capital 499

$10 \S 13$ 'Other state expenditure': contingent expenditure and required expenditure on especially 'too big to fail' banks $\quad 502$

Division 4. The vulnerabilities of the state's reach $\quad 504$

$10 \S 14$ Vulnerabilities and impossible necessities $\quad 504$

Summary and conclusions $\quad 507$

Appendix 10.A. Data and data sources of the graphs in chapter $10 \quad 5 \circ 9$

List of figures chapter $10 \quad 5^{20}$ 


\section{Introduction}

This chapter presents the reach of the capitalist state in three of its concrete manifestations.

The first division - which is the sequel to Chapter 5 - shows how the development of the size of the state in terms of its expenditure modifies the cyclical accumulation of capital. More specifically, a structurally increasing state expenditure decreases the amplitude of the cycles.

Whereas Chapters 6-9 presented the content of the state's regulation, Division 2 presents the manifestation of the state in the character of legislation and other regulation. It will be shown that, for various reasons, not only does the amount of regulation increase over time, but also the dynamic of regulation inevitably results in more complicated as well as more complex regulation.

Division 3 presents a synthetic overview of the state's manifestation in its expenditure. Although all expenditure categories will be briefly reviewed, the main focus in this division will be on social security expenditure and the problematic thereof for the state and hence for the capitalist system.

A brief final division, called 'the vulnerabilities of the capitalist state's reach', takes some threads of Divisions 2 and 3 together. Whereas Chapters 6-8 successively presented the conditions of existence of the state - vis-à-vis the capitalist economy with which it constitutes a separation-in-unity - the final division detects the major vulnerabilities in these conditions of existence. In other words, it detects the potential impediments to the continued reproduction of the capitalist system.

Scheme 10.1 presents the outline of this chapter.

\section{Division 1. The size of state expenditure and its effect on the amplitude of the capitalist economic cycle}

This division considers how the state and its expenditure are manifested in the cyclical movement of capital as set out in Chapter 5 . As such it is the sequel to that chapter.

\section{$10 \$ 1 \quad$ The size of the state: state expenditure as mitigating economic recessions}

This section briefly outlines the general effect of state expenditure on the cyclical accumulation and over-accumulation of capital (Chapter 5).

[continued] 
SCHEME 10.1 The reach of the capitalist state (outline Chapter 10)

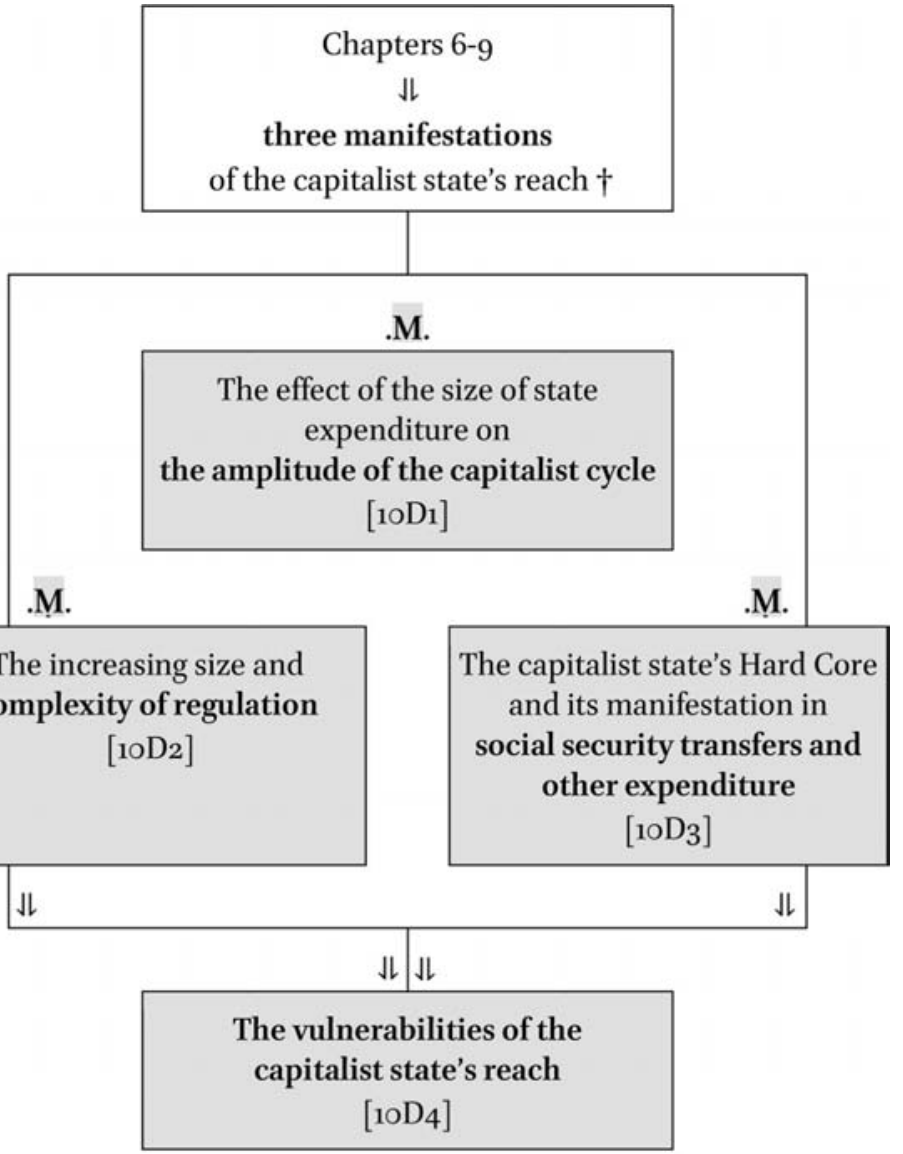

Legend

.M. concrete manifestation

$\sqrt{ }$ bottom moment derives from top moments

$\dagger \quad$ The three manifestations regard the first three moments (10D1-10D3). The last moment (10D4) builds on $\mathrm{1OD}_{2}$ and $\mathrm{1OD}_{3}$ in a particular synthetic manner.

\section{$10 \$ 1$ Continued}

Generally the degree of state expenditure (measured as a percentage of GDP) affects the potential degree of its mitigating the amplitude of the cycle.

'Potential', that is, when the state does not expend pro-cyclically. Thus to the extent that in a recession the state maintains its expenditure, it puts a considerable floor in the general cyclical expenditures (that is, state expenditure together with private investment and the consumption that is independent 
of social security transfers). Then, to the degree that state expenditure is structurally large in comparison with the private sector, the composition of the potentially non-volatile general expenditure (that of the state) and the potentially volatile expenditures (those of private investment and the transfersindependent consumption) structurally changes in favour of the non-volatile expenditures, so that the general cyclical volatility decreases. In other words, state expenditure acts as an automatic stabiliser. (See further Amplification 1०§1-a.) This effect is independent of any discretionary counter-cyclical policy (see $10 \S 2$ ).

Given the floor of state expenditure (and provided the state abstains from pro-cyclical policy) the course of the capitalist business cycle is broadly as presented in Chapter 5 , though with a moderated amplitude of the cycle. This would be one aspect that positively contributes to the legitimation of the state and so the capitalist system as a whole (that is, amongst the negative and other positive aspects). Actors, however, tend to evaluate the cycle 'within their own times' - that is, given the 'normal' size of the state within their own times.

10§1-a Amplification. Historical changes in the amplitude of the cycle along with changes in state expenditure

In the first two sub-sections of this amplification there is no mention of state expenditure; these two sub-sections are merely on observations about amplitudes.

(1) The amplitude $1870-1989$. For a sample of 16 current OECD countries, ${ }^{1}$ Maddison (1991, pp. 3-4) shows 'that peacetime business cycle history has been much milder since the Second World War than before, and that the 1920-38 period was generally much worse than 1870-1913.' He produces the following average 'amplitude of recessions in aggregate output, 1870-1989: maximum peak-trough fall in GDP or lowest rise (annual data)'.

$187^{-1913} \quad 1^{1920}-3^{8} \quad 195^{\circ-73} \quad 1973^{-89}$

amplitude in \% of GDP: arithmetic
average for 16 current OECD countries

1 OECD-21 minus Greece, Ireland, New Zealand, Portugal and Spain. 
Maddison mentions that this average for the group is dampened by the fact that individual country cycles are not synchronised.

(2) The amplitude 1990-2000. In a 2002 OECD working paper, Dalsgaard, Elmeskov and Park observed that for a sample of 13 OECD countries, ${ }^{2}$ the amplitude of the business cycle for most of these, when proxied by the average size of output gaps over ten-year periods, declined in the period 1980-2000 in comparison with the decade of the 1970s (Dalsgaard, Elmeskov and Park 2002, p. 7). 'Divergencies of output gaps across OECD countries have diminished since 196o with a particularly strong tendency since the early 199os' (Dalsgaard, Elmeskov and Park 2002, p. 23).

In an IMF publication, Kannan, Scott and Terrones (2009) show that from the mid-1980s (and until 2007) there was an even further moderation. (See $10 \S 2$-a for their findings concerning financially driven crises.)

As an illustration Graph 10.2 shows, for a much longer period, the amplitude in growth rates of real-GDP per capita for the USA. ${ }^{3}$

(3) Amplitude and size of government expenditure. As the thesis that the increasing size of government expenditure mitigates the amplitude of business cycles (main text 10§1) does not quite fit in with most mainstream economic models, this sub-section quotes empirical research in this field. In an OECD working paper empirically assessing government budgets in relation with business cycle amplitudes in the 1990s for 20 OECD countries (OECD-21 minus Switzerland), Van den Noord observes:

'The most important factor determining the cyclical sensitivity of the fiscal position is the size of the general government sector. For the most part, the larger the share of government expenditure in domestic output, the greater is the sensitivity of the fiscal position to fluctuations in economic activity ... The tax structure also has a significant impact on the size of automatic stabilisers: the higher the taxation of cyclically sensitive tax bases, the more the tax take will vary with the business cycle and hence the greater will be the cyclical sensitivity of the fiscal position. The progressivity of taxes, the generosity of unemployment benefits and the cyclical sensitivity of various tax bases and unemployment,

2 OECD-21 minus Belgium, Denmark, Finland, Greece, Ireland, Netherlands, Portugal, Switzerland.

3 We also see a considerable decrease in amplitude for Japan and especially France. In some countries, such as the UK and Italy, the decrease is much less pronounced. In Germany, the decrease is also considerable compared with the period 1920-38; for this country, however, the amplitudes in the period $1870-1913$ were rather moderate (between $+6 \%$ and $4 \%)$. 
GRAPH 10.2 Growth amplitudes as measured by the growth rate of real-GDP per capita, USA 1870-2015 in 2011 prices (annual data). Panel 1: all years; panel 2: the world wars related years (1914-19 and 1939-49) dropped
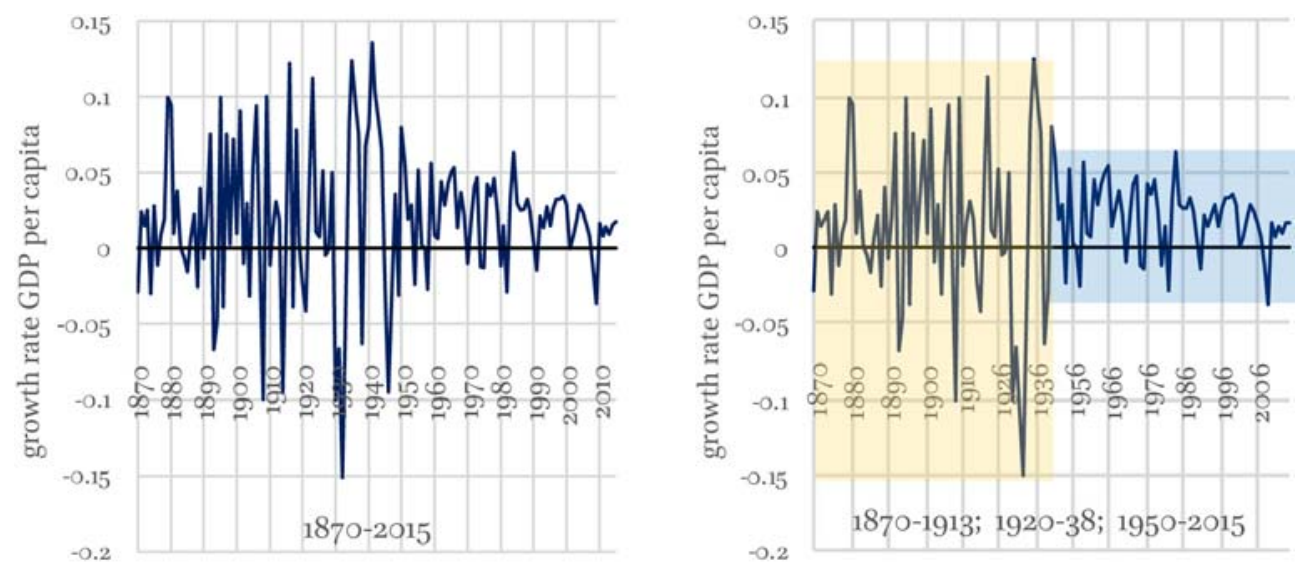

DATA SOURCE: Maddison Project Database, version 2018 by Jutta Bolt, Robert Inklaar, Herman de Jong and Jan Luiten van Zanden ${ }^{4}$

finally, are other significant factors in determining the cyclical sensitivity of the fiscal position.'

200o, p. 7 , italics in original ${ }^{5}$

Earlier Galí (1994) showed that for a sample of 22 OECD countries (OECD-21 minus New Zealand plus Iceland and Luxembourg), 196o-9o, 'both taxes and government purchases seem to be effectively working as "automatic stabilizers".' Economies with 'large governments' 'have experienced milder economic fluctuations than economies with "small governments"' (Galí 1994, pp. 130-1). Galí considered the stabilising effect of the ratio of government purchases over GDP (government expenditure minus wages and transfers).

Fatás and Mihov (2001) consider the total of government expenditure for 20 OECD countries covering the years 196o-97. They find:

'a strong negative correlation between government size and output volatility ... This correlation is robust to the inclusion of a large set of controls as well as to alternative methods of detrending and estimation. In

4 https://www.rug.nl/ggdc/historicaldevelopment/maddison/releases/maddison-project -database-2018 (CGDPpc set), update 11 January 2018. See also Bolt, Inklaar, de Jong and Luiten van Zanden 2018.

5 Van den Noord also observes that in some countries governments' "discretionary actions ... have reduced, or even offset, the effect of automatic fiscal stabilisers" (abstract). 
the international sample, a one percentage point increase in government spending relative to GDP reduces output volatility by eight basis points.'

Their abstract

They also observe (in reference to Van den Noord 200o):

'Traditionally, the stabilizing role of fiscal policy has been associated to the size and volatility of the budget deficit and not the budget itself. Although, as we have argued before, there is evidence that overall size and responsiveness of fiscal variables are strongly correlated, our results raise the question whether the size of governments is important in itself.'

FATÁs and MIHOV 2001, p. 18

Fatás and Mihov (2002/2003) reach similar results for a sample of $5^{1}$ countries covering $1960-99 \cdot{ }^{6}$ (In the same paper they also study the effect of pro-cyclical policy. $)^{7}$ By the year 2008, Andrés, Doménech and Fatás (2008) can refer to the thesis that large governments are associated with less volatile economies as being an empirically well-established 'stylized fact' that has been refined by several recent studies. ${ }^{8}$ They confirm the earlier results for 20 OECD countries (OECD-21, minus New Zealand and Switzerland plus Turkey) covering the period 1960-2004. (Much of this paper - as is Fatás and Mihov 2002/2003) as well as other literature in the field since Galí (1994) - is concerned with the question of how this empirical fact could (or cannot) be accounted for in an amended 'real business cycle' model.

I close this sub-section by noting that, generally, international synchronisation of business cycles would, by itself, have an amplitude increasing effect. Dalsgaard et al. (2002) observe: 'international divergencies of cyclical positions have diminished but, outside the euro area, there is little evidence of increased synchronisation of cycles' (their abstract; see also p. 9 and especially note 15). This is different for recessions with financial origins, to which I briefly turn in the next section.

6 See esp. working paper version (2002) pp. 15 and 27.

7 They somewhat misleadingly define 'discretionary policy' as 'changes in fiscal policy that do not represent reaction to economic conditions.' They add: 'In theory, it is useful to think about fiscal policy as consisting of three components: (a) automatic stabilizers, (b) discretionary fiscal policy that reacts to the state of the economy, and (c) discretionary policy that is implemented for reasons other than current macroeconomic conditions.' (working paper version pp. 3-4) Regarding the last component (c) they find that the volatility of output induced by [this] discretionary fiscal policy lowers economic growth by o.6 percentage points for every percentage point increase in volatility, and that 'there is evidence that the increase in volatility is in part due to electoral cycles; nevertheless, we do find that political constraints restrain fiscal policy beyond their impact on the traditional election-year volatility' (abstract).

8 Abstract and working paper version p. 13 . 


\section{$10 \$ 2$ State policy in recessions versus depressions}

Given the capitalist state's furthering the accumulation of capital $(7 \S 3)$ and given that the incentives for the accumulation of capital result in cyclically recurrent over-accumulation of capital $(5 \S 8)$, it seems that the state is bound to passively await the cyclical curing of that over-accumulation $(5 \S 9) .{ }^{9}$ With considerable automatic stabilisers there is, in ordinary recessions, generally no necessity for additional state policy. Keeping state expenditure and state expenditure commitments as well as tax rates unaffected puts a floor into the general macroeconomic expenditure during recessions (10\$1).

However, when a recession takes on the character of a depression (a prolonged recession - often triggered by a financial crisis and bank failures and often in combination with price deflation), the mere state expenditure floor may not be a sufficient base for getting to a recovery via restructuring of capital $(5 \S 9) \cdot{ }^{10}$ Then the reproduction of the capitalist system requires a substantial discretionary state policy. As Keynes (1936) indicated, monetary policy is not likely to be sufficient in a depression, whence the state is required to engage in substantial additional spending. ${ }^{11}$ (See also Kannan, Scott and Terrones 2009.)

10§2-a Amplification. Frequency of recessions/depressions associated with financial crises, and their severity and duration comparison with non-financial ones

In an empirical IM F study, Kannan et al. conclude that:

'recessions associated with financial crises tend to be unusually severe and that recoveries from such recessions are typically slow. Similarly, globally synchronized recessions are often long and deep, and recoveries from these recessions are generally weak. Countercyclical monetary policy can help shorten recessions, but its effectiveness is limited in fin-

$9 \quad$ Though see Addendum $10 \S 2$-b on indicative planning.

10 In a 2008 IMF working paper, Claessens, Kose and Terrones characterise a depression as 'an extremely severe recession, in which the peak-to-trough decline in output exceeds 10 percent' (2008, p. 15). Kannan et al. (2009, p. 5) also take this view.

The three periods of 1873-96 (esp. for the UK and somewhat briefer for the USA), of 1929 until wwII, and of 2007/08 and after have been identified as depressions (see, e.g., http:// www.nytimes.com/2010/06/28/opinion/28krugman.html?_r=o). Note, however, that the state expenditure floor has considerably increased since the second depression.

11 In much of the post-wwiI period, Keynes has been looked upon as a business cycle theoretician (this is what at least the Neo-Keynesians made of him). In my view - and apart from its theoretical innovations - his 1936 work makes Keynes primarily a depression economist. 
ancial crises. By contrast, expansionary fiscal policy seems particularly effective in shortening recessions associated with financial crises and in boosting recoveries.' (2009, abstract)

These conclusions are based on evidence from a sample of 21 OECD countries (the OECD-21) for the period 1960-2007, excluding emerging financially originating recessions in their last year (2007). Of the 122 recessions in their sample, 15 are associated with financial crisis (i.e. $12 \%) .{ }^{12}$

GRAPH 10.3 Average number of recessions per decade and per country $1870-$ 2008 , for a sample of 14 current OECD countries ${ }^{13}$

average total number of recessions per country per decade

of which associated with financial crisis

- percent of financial associated ones (numbers at the top)

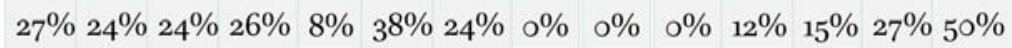

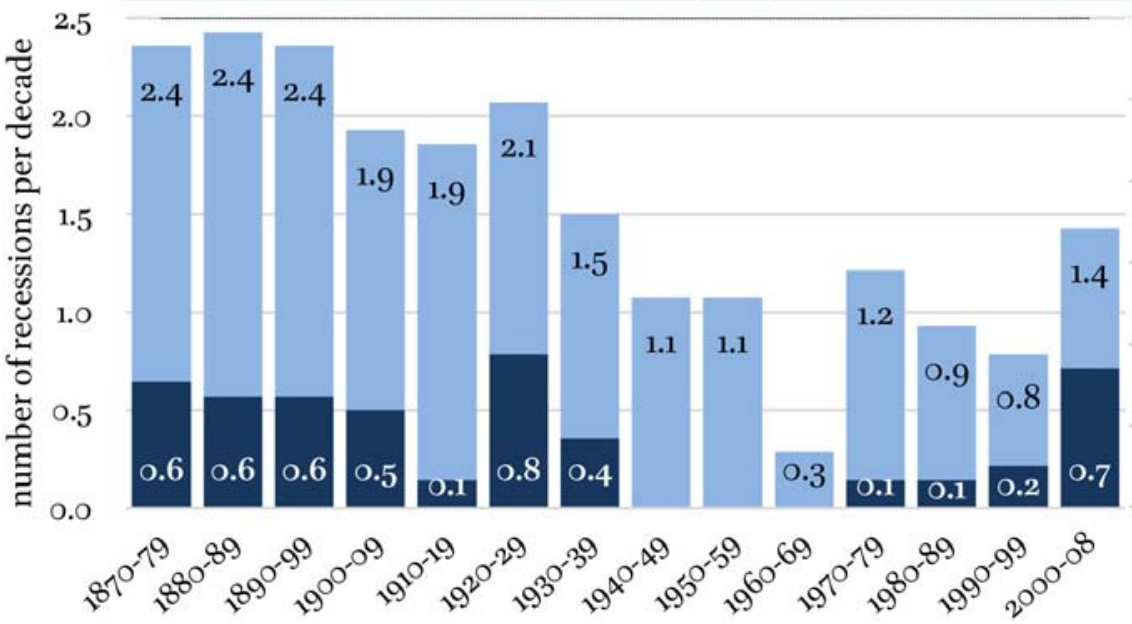

DATA SOURCE: calculated from Jorda, Schularick and Taylor 2012, Table 1

Jorda, Schularick and Taylor (2012) go back to 1870 for a sample of 14 OECD countries. ${ }^{14}$ They do take into account the 2007/08 financial crises. For their sample $22 \%$ of the recessions/crises in this period are of financial origin. However, doing a calculation from their sample, which restricts to the 196o-

12 Kannan et al. 2009, p. 8. The last financially associated crisis within their sample dates from 1997q2-1999q1 in Japan.

13 See the previous note.

14 The oECD-21 minus Austria, Belgium, Finland, Greece, Ireland, New Zealand, Portugal. (See $7 \S 3$-c for the 'OECD-21’). 
2007 period (and excluding the 2007/08 financial crises as do Kannan et al.) results in $11 \%$ of the recessions/crises in this 1960-2007 period being of financial origin. This is not far removed from the $12 \%$ of the Kannan et al. data for 21 countries.

In this light - and given that this chapter is confined to broad outlines that go back to early full capitalism - Graph 10.3 shows decade averages that I have calculated from the sample of Jorda et al.

Noting that severity of recessions (10§1) is at least as important as their frequency, it can be seen from Graph 10.3 that, roughly, there is a downward trend in the average number of cycles per decade, and that, especially after 1910, crises from financial origin are an irregular phenomenon. ${ }^{15}$

Kannan et al. (2009, p. 10) indicate - for the period 1960-2007 - that credit growth during the expansions preceding financial crises is higher than during other expansions, and that credit booms have frequently followed financial deregulation.

10§2-b Addendum: French and Japanese indicative planning Given the cyclically recurrent over-accumulation of capital, which gives rise to recession and destruction of capital, it is not a ludicrous idea for a capitalist state to try to prevent such over-accumulation. Throughout the 1960s and $1970 \mathrm{O}$ the French and the Japanese states institutionalised, in various ways, an 'indicative investment planning' (non-binding investment schedules that combine forecasts and planning). On the French variant see, for example, Dalton (1974, pp. 154-60), Bonnaud (1975, pp. 93-110) and Nielsen (2008). On the Japanese variant see, for example, Caves and Uekusa (1976a; 1976b), Trezise and Suzuki (1976) and Nielsen (2008).

\section{Division 2. The increasing size and complexity of regulation}

The state's eight regulative frameworks (Chapters $6-7$ and 9), as well as the forms and design of taxation (Chapter 8), engender an increasingly complicated, as well as complexity of, regulation. This division is not about the content of regulation and tax legislation; rather it concerns the characteristics that determine their reach. Because this division will introduce a lot of interconnected concepts within few pages, it is probably one of the more difficult ones

15 For graphs of the GDP growth effects of financial crises 1975-2015 see https://knoema.com/ xflgvk/40-years-in-financial-crises. 
of this book. At the same time it is a key one. In the conclusions to this chapter I will state that the inevitably increasing quantity, complication and complexity of regulation within capitalism is one of the latter's core vulnerabilities.

\section{$10 \S 3$ Regulation: laws and delegated regulation}

Much of the organisation and terminology of the legislative and regulatory frameworks is country-specific. Generally the 'rules framework' includes 'primary legislation' (laws/acts), which is passed at the highest administrative level, and 'secondary legislation' (other rules), which is passed at lower administrative levels (including field-specific regulatory bodies). The former formally provides the delegation for the latter, and may also withdraw this delegation. Secondary legislation is often more detailed or field specific.

Though in most countries (and all of the OECD-21) there is this distinction, what is allotted to different levels is highly contingent (also within one country). ${ }^{16}$ This is a matter of institutional organisation and of the possible speed of change of a rule (speedier for delegated legislation). Further, for actors the level makes no difference: the required compliance is independent of the level.

For the purposes of the current division, therefore, I adopt the following terminology. I use the term regulation for the entirety of laws and of the 'delegated regulation'. When I explicitly refer to the latter I always use the adjective 'delegated'. When I refer to 'regulation', as said, this refers to the entirety. I refer to one particular regulation as 'a' regulation or, in case of a set, 'regulations'.

10§3-a Amplification. Execution of delegated regulation: 'orders' This amplification is not relevant for the further main text, though it is relevant for especially Amplification 10\$5-a.

Delegated regulation may be promulgated by executives (such as presidents), governments, ministers or other executive bodies (especially regulatory agencies), always depending on the type of delegation as formulated in the laws (sometimes in the constitutional law). Specific types of delegated regulation go under different names in different countries. In this division I merely use the term 'order': presidential order, government order (or order in council), ministerial order, field order (the latter referring to the orders of a designated authority within, or under the supervision of, a ministry - also called regulation agencies or authorities).

16 Parliaments may in some cases require detailed primary legislation (on which they have more influence); in other cases their concern is to delegate detail. 
In what follows I will not refer to further various country specific names for these, such as 'regulation' (for the entirety of the delegated regulation), 'statutory instruments, 'codes', 'rules' or 'decrees.'17

\section{$10 \S 4$ A conceptual outline of the reach of regulation: lack of operational measures}

This section is a preview. Clarifications are set out in the sections to come. Figure 10.4 provides a conceptual outline of the rest of this division. The following $10 \S 5$ starts with the quantity of regulation. (See the section indications at the left hand border of the figure.) Next we move to the degree of complexity of regulation (10§6) and finally to the change of regulation (10\$7). Almost all of the concepts outlined concern 'degrees' (of complexity, for example) as indicated at the right hand border of the figure.

The economy-wide total quantity of regulation is determined by the 'densities' of regulation in regulation fields (e.g. banking, telecommunication or shoe repair); the density being determined by whether a field is covered at all by regulation, and in what degree of intensity (highly or barely regulated; this regards the degree of detail of regulations).

The degree of complexity of the regulation in a field - and, summed, the total complexity - is determined by the degree of 'complication' of regulation, and the degree in which the regulations in one field (e.g. regarding competition) are 'interwoven' with other regulations in that field or adjacent fields (e.g. taxation). Additionally, complexity is also determined by the degree in which economic actors (the subjects of regulation) dynamically 'fuse' fields of regulation (especially by product and process innovations). Despite the importance of the latter two, I will show that 'complication' is in effect the key concept for the reach of regulation.

The dynamics regarding regulation come together in the factors that drive the continuously changing regulation. These drives (unintended loopholes in regulations; and new or re-perceived social-economic problems) tend to increase not only the (initial) density of regulation - by its determinants of coverage and intensity - but especially also the complication of regulation. (See the dotted arrows in Figure 10.4.) Despite factional political efforts and wideranging actors' demands to roll back regulation, or (in my view rather naïve) demands to at least decrease complication, I will conclude in $10 \$ 7$ that, for the

[continued]

17 For the US case see, e.g., http://dictionary.law.com/Default.aspx?selected=1771 (or http:// legal-dictionary.thefreedictionary.com/regulation.)

For the UK see, e.g., https://www3.law.ox.ac.uk/lrsp/overview/legislation.php. 
FIGURE 10.4 Conceptual outline of the reach of regulation

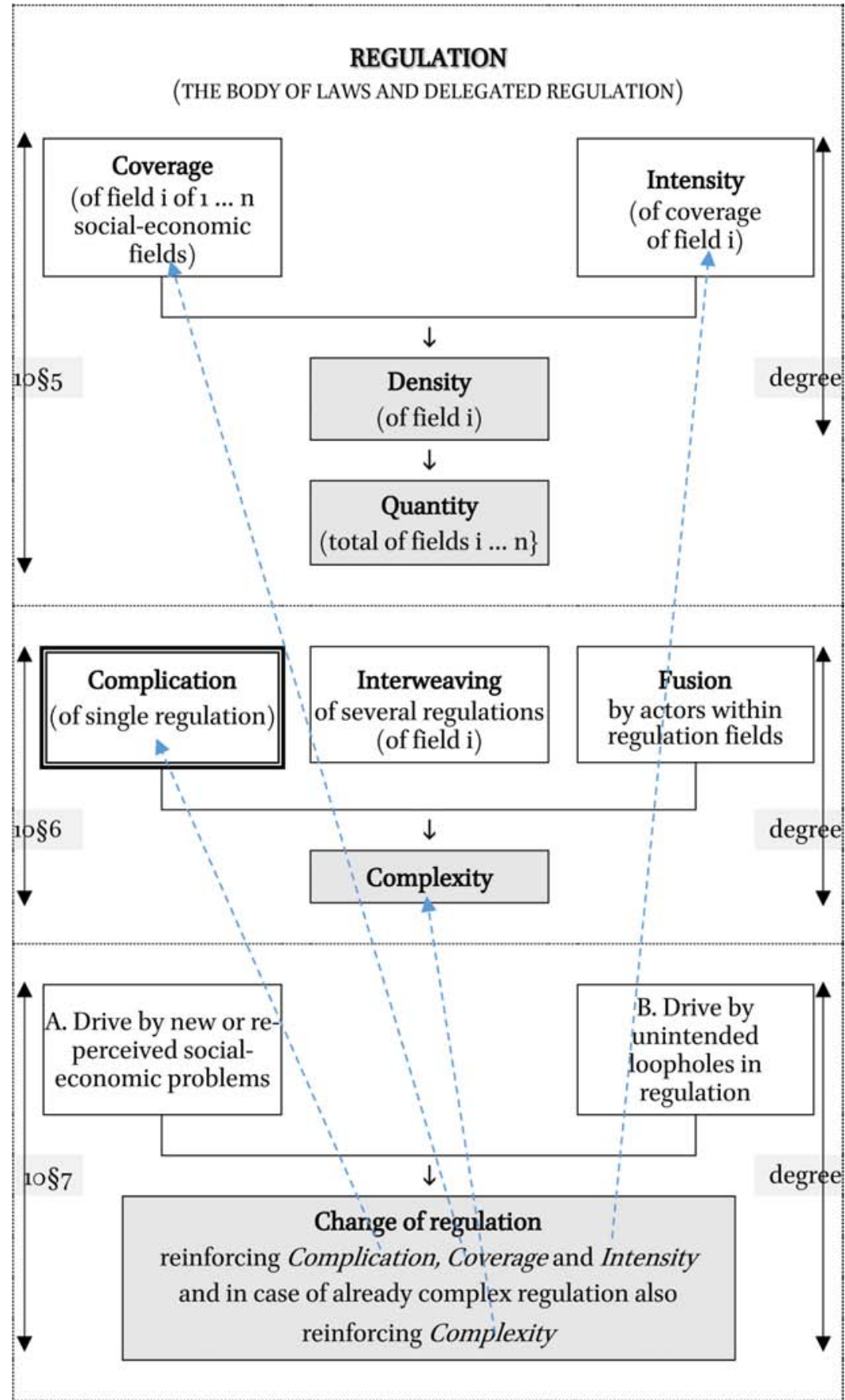




\section{$10 \$ 4$ Continued}

capitalist system to survive, a continuously increasing complexity of regulation is inevitable.

All along the following exposition we will be confronted with the problem that - apart from the mere quantity of regulation - this research field lacks operational measures for key concepts.

\section{$10 \S 5$ Quantity and density of regulation: (too) simple measures}

A fair amount of attention has been given to complaints about the amount of regulation and, along with it, efforts to push the state back. ${ }^{18}$ Note, however, that there are also pressures to increase regulation (pulling the state in). Think of various property claims and of tax and non-tax subsidies. In the field of competition policy we have the push and pull pressures on the same terrain. Enterprises seek to push out the state for their own non-rivalrous (anti-competitive) supply activities, though they pull in the state for their own purchasing activities for which they seek competition. The same applies for regulation of the quality of output and production, including for concerns of health and a sustainable environment such as the climate: regulate them, not us! However, once regulation is generally deemed inevitable, enterprises want parity. Simultaneous push and pull pressures, and next parity requests, also apply for social security.

More generally, change of the economic structure calls for extension of regulation (for example, the evolution of traffic and of ICT). As 'old' processes and products only gradually die off (if at all), we have an increase in the quantity of regulation. Scrapping of regulation is rare (unless some surviving together with an evolving field is covered by a brand new law).

Mere Quantity. The simple question of how much regulation there is in force in a country is already difficult to answer (see Amplification 10 $\$ 5^{-a}$ ). However, counting titles of laws and other regulation is not particularly telling because their size is highly divergent, ranging from tens to many thousands of pages for one title (the latter, for example, for the 'Code civil' in French oriented codes). ${ }^{19}$

18 See, for example, the OECD publications on administrative simplification http://www .oecd.org/gov/regulatory-policy/administrative-simplification.htm as well as its series of country studies on regulatory policy http://www.oecd.org/gov/regulatory-policy/by -country.htm and KPMG International (2011). The latter document includes a questionnaire among worldwide top-management on complexity of management in general. Complexity of non-tax regulation ranked highest ( $71 \%$ of respondents) and that of complex tax regulation somewhat lower ( $57 \%$ of respondents). For these managers at least, it seems that the coping with regulation dominates much of their job. 
Some researchers propose to add up the sections of regulation, ${ }^{20}$ but their sizes also highly diverge, especially between country traditions. A better simple measure seems to count pages, though with the qualification that these are layout dependent. ${ }^{21}$ Even if the stock of regulation at some initial date were unknown, one could still count the rate of mutation of the quantity of regulation (Amplification $10 \S 5$-a provides an example.)

Whatever measure one adopts, the common opinion between researchers in this field is that the quantity of regulation has enormously increased between the end of the nineteenth century, or between halfway through the twentieth century, and the early twenty-first century. The main question is merely whether or not in some periods the speed of increase has slowed down. ${ }^{22}$

Density. As indicated in $10 \$ 4$, the total quantity of regulation is determined by the density of regulation in each field. The latter is again determined by, first, the fields that are covered at all by any regulation, and second, by the degree of intensity of regulation in those fields, that is, the degree of detail. ${ }^{23}{ }^{24}$ (See the first block of Figure 10.4.)

Each of these could in principle be counted, the latter (intensity) in a very rough way by the number of pages of regulation, assuming for the time being that - in one country - these are of equal complication (see the next section).

Quantity, impact and measures. Measures of mere quantity of regulation are defective in measuring the impact of regulation because these do not measure the complexity of regulation (see the next section). For the latter, however, adequate operational measures are lacking so that for long run and for between country comparisons we have no more than simple quantity measures.

$20 \quad$ For example, de Jong and Herweijer 2004, p. 57.

21 The best simple measure would be a word count (supposing digitalisation), but I have not seen word count based quantifications.

22 Note though that towards the end of the coming into office of a government, the quantity of legislation passed is usually higher than at the beginning (due to legislation preparation effects).

23 For 'field' one can refer to the SNA (System of National Accounts) economic sector division at some digit level. Next there is the general regulation that applies across fields (Chapters 6-7 and 9).

24 Van Gestel and Hertogh (2006, p. 31) and Van Gestel (2011, p. 8 n. 5) adopt the term 'density of regulation' for the combination of Quantity (Coverage and Intensity) and Interweaving. They do not cover Complication and Fusion, and hence not Complexity of regulation. 
$10 \S 5$-a Amplification. Some examples of simple quantifications of the amount of regulation

Even the mere adding up of the titles of all of the regulation in force is painstaking work that is not often undertaken (however, recent mutations are well known).

Limited country-wise information about the total quantity of regulation in force. In terms of estimating the number of usa federal laws in force, Shameema Rahmana, a senior legal research specialist at the USA Library of Congress, writes in 2013: 'trying to tally this number is nearly impossible.'.25

A 2013 report of the UK Office of the Parliamentary Counsel mentions: 'It is extremely difficult to estimate how much legislation is in force at any one time.' (p. 6; the difficult estimation is not undertaken by the office. $)^{26}$

Graph 10.5 shows some data for the laws in force of the Netherlands. (This is an example; in 2015 the country ranked 17 th in terms of world GDP. Whereas that rank does not seem important for the quantity of regulation - any country has to regulate - there can be cultural differences in the degree of delegation including 'orders'.)

GRAPH 10.5 Number of laws in force, the Netherlands 1980-2015 (central government, exclusive delegated and EU regulation)

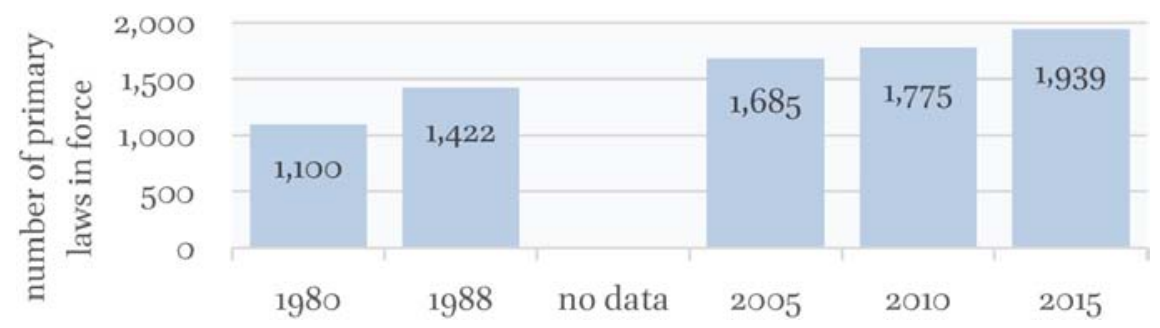

DATA SOURCES: 1980 and 1988 (Overhoff and Molenaar 1991, pp. 5-6); ${ }^{27} 2005$ and 2010 (Government of the Netherlands 2013; 2015; Vester 2017)

25 http://blogs.loc.gov/law/2013/o3/frequent-reference-question-how-many-federal-laws -are-there/.

Apparently in the USA around 2010, each year some 100 brand new bills are passed into law http://www.kowal.com/?q=How-Many-Federal-Laws-Are-There\%3F.

26 On the mutation it states: 'Every year, new legislation and amendments result in over 15,000 (over 30,000 when considering secondary legislation) legislative effects' (p. 7).

27 Quoted in de Jong and Herweijer 2004, p. 19. 
Regarding primary laws there is limited historical information (Graph 10.5). It can be seen that in the 35-year period 1980-2015, the number of laws in force increased by $76 \%$. Information on delegated central government regulation is even more limited (available only from 2004). In 2015 there were for this country 9,136 central government regulations in force (exclusive regulatory agencies and exclusive EU regulation). These comprised 1,939 laws (21\%) and 7,197 orders in council and ministerial orders $(79 \%) .{ }^{28 \mid 29}$

I now turn to the EU regulation that is not included in the numbers above.

Quantity of regulation in force: the EU. EU regulation consists of two main categories. One category regards the so-called 'directives'. Because national governments are obliged to implement these directives in their national regulation, these should not be added to the national quantities of laws in force (thus the 'implementations' are included in the numbers of the example of the Netherlands above). All the other EU regulation is not implemented in national regulation, thus this is regulation that is additional to the national ones. This other EU regulation is summarised in Graph 10.6. Note that the EU jurisdiction is mainly economic and monetary, excluding jurisdiction on especially taxation and social security legislation (though there are exceptions).

The area charts at the bottom of Graph 10.6 show the quantitative development of the delegated EU regulations newly issued from 1967. These come in two main types. The fist type includes orders with usually a general character (the EU calls these 'Regulations' that I write with a capital R to differentiate these from the genus 'regulations'). The second type includes orders with usually a specific character ('Decisions'). The three bottom charts show that after a considerable increase from 1967-95 (a factor of 8 for the total) - which relates to the EU's establishment - the issue of new regulation slows down afterwards, but nevertheless keeps forthcoming considerably (a number of 1,864 in 2012).

As an indicator for the stock of delegated regulation in force, we can use the delegated general regulations ('Regulations') without an expiry date, corrected for repeals - see the columns in Graph 10.6. In 2012 their total was 21,792. Their increase from even $1995^{-2012}$ amounts to a factor of 9 .

\footnotetext{
28 See Vester 2017.

29 For another example I point to information related to a pages count regarding newly issued central government laws and delegated regulation of Finland (excluding regulatory agencies and excluding EU regulation). As such this is not about the stock of the regulation in force. This newly issued regulation increased from 1,0oo pages per year in 1920 to just over 2,ooo pages in 1985 and to 3,500 pages in 2000 (de Jong and Zijlstra 2009, p. 139; from the Finnish Government 2002).
} 
GRAPH 10.6 Number of total delegated regulations issued each year, and cumulative total of the delegated general regulations without expiry date; European Union 1967-2012 30

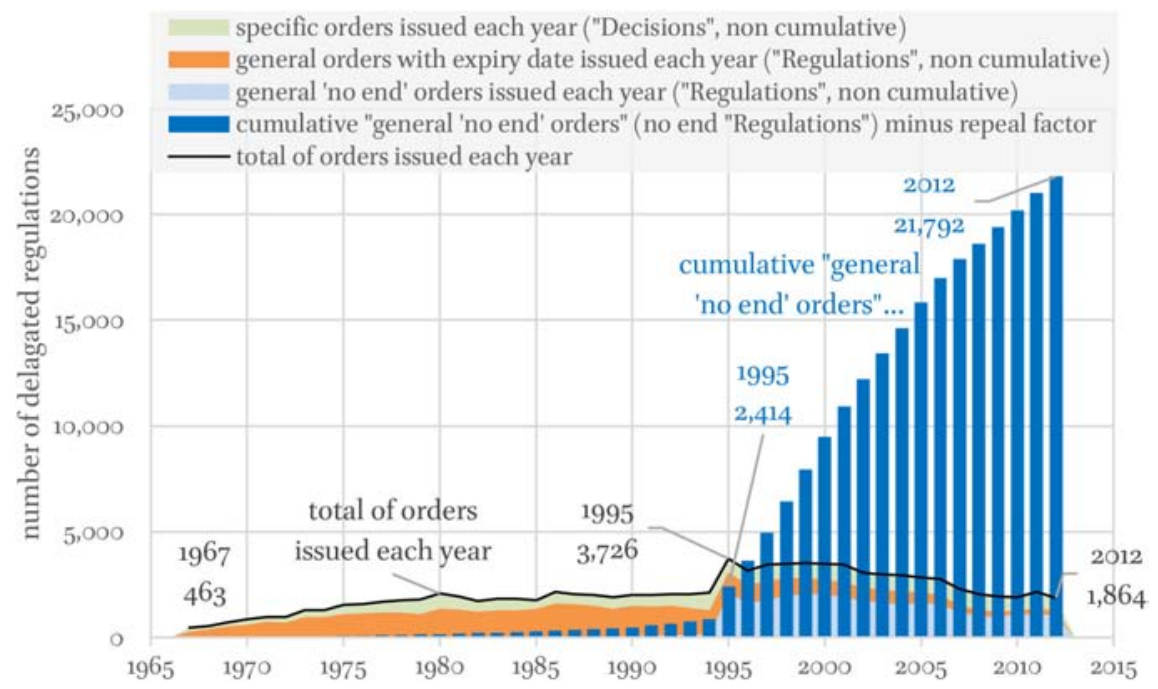

DATA SOURCE: Toshkov $2014^{31}$ and House of Commons [UK] 2010, p. $13^{32}$

Stock of delegated federal regulation in the USA: number of pages. Even if, as noted above, for the USA the stock of federal laws is apparently unknown, there are data for the stock of the federal 'delegated regulation' that not only go back to 195 , but also provide this information in terms of number of pages (see Graph 10.7).

The USA Code of Federal Regulations (CFR) annual edition is 'the codification of the general and permanent rules published in the Federal Register by the departments and agencies of the Federal Government.'33|34

30 A restricted forerunner of the EU dates from 1957. The starting date for the Graph below is 1967 , the year of the creation of a single Commission and a single Council to serve the then three European Communities (EEC, Euratom, ECSC).

31 http://www.dimiter.eu/Eurlex.html / http://www.dimiter.eu/Data.html [February 2014 $\rightarrow 19$ December 2015].

32 From the repeal of regulation (all regulations) provided by the last source for 1997-2009, an average repeal ratio of $25 \%$ can be calculated. To be on the safe side I have applied this ratio to Regulations without expiry date from Toshkof's database. (Their repeal ratio is probably less than the average for all Regulations.)

33 https://www.gpo.gov/fdsys/browse/collectionCfr.action?collectionCode=CFR.

34 The CFR is a stock measure that is to be distinguished from the Federal Register's data on the annual flow of new regulation. Measured in pages this flow increased considerably 
GRAPH 10.7 Development of the quantity of delegated regulation in force at the federal state level in the USA: total number of pages 1950-2015

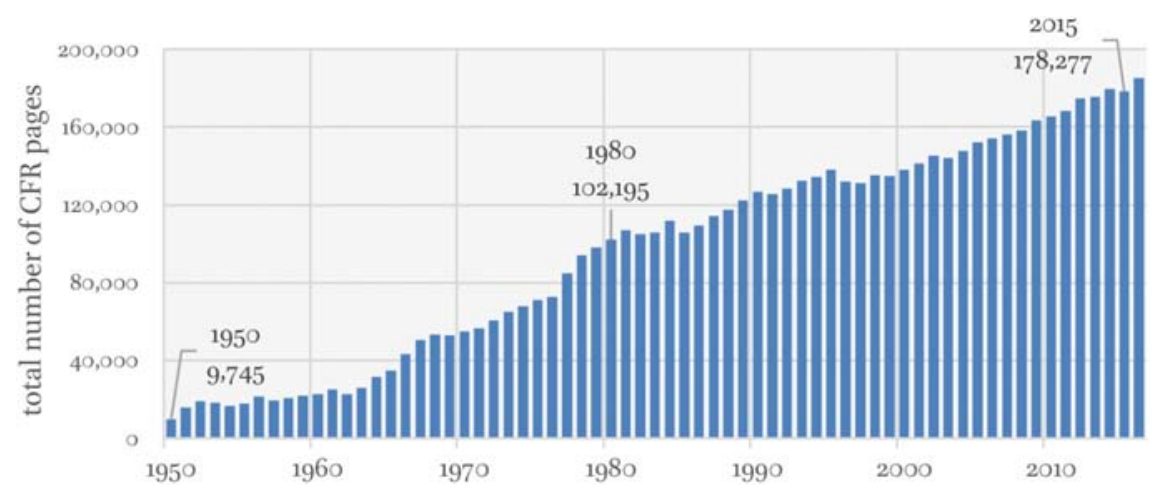

DATA SOURCE: USA Federal Register, Code of Federal Regulations $(2017 / 04)^{35}$

Graph 10.7 shows that the pages increase of the delegated regulation in force is quite enormous (between 1950 and 2015 there is a factor increase of 18 ). If the increase were to continue at the same rate, then the number of pages will have increased to one million by 2050 . Note, however, that the 178 , ooo pages of Federal delegated regulation in force in 2015 far from measures the total quantity of regulation for the actors in some US state. In a 2015 OECD report, it is mentioned that of the total number of laws (i.e. federal plus local state), only $1.7 \%$ are national, i.e. federal - a number for the similar proportion of the delegated regulation is not provided. ${ }^{36}$

from 1937-70. From 1970-80 the increase accelerated, next dropped until 1985 and then again gradually increased afterwards. However, from the mid 1970's the flow of the number of new 'final rules' decreased (with fluctuations) from 7,401 in 1976 to 3,281 in 2017 (the latter numbers reveal that the pages count is relevant). Carey, 2016, provides qualifying comments on these flow measures. For a pages count of the stock (CFR), and especially the long term trend thereof, these qualifications are less relevant (one of his correct points is that the elimination of an existing rule is executed by a new rule; however, in terms of pages this is usually not weighty, and it is likely that such drops occur throughout time). https://www.federalregister.gov/reader-aids/understanding-the-federal-register/federal -register-statistics $\rightarrow$ Code of federal regulations, Total Pages and Volumes 1936-2016 (xls) $\rightarrow$ tab CFR volumes (2017/04, accessed 1 February 2018). See also https://www .federalregister.gov/blog/learn/tutorials, Federal Register \& CFR Publication Statistics Aggregated Charts. A similar graph can be found at the website of the Regulatory Studies Center, George Washington University; Regulation statistics http://regulatorystudies .columbian.gwu.edu/reg-stats.

36 OECD 2015a, Annex A. [OECD Regulatory Policy Outlook 2015.] 
In conclusion of this amplification. Even the data we have on merely the quantity of regulation is limited. The available information points to considerable increases over time.

\section{$10 \S 6$ Complexity of regulation: the combination of complication, interweaving and field fusion}

The degree of 'complexity' of regulation lies in the combination of the 'complication' of single laws or orders, and of the 'interweaving' of several laws and their lower level orders. Additional complexity arises through 'field fusion'. (Sub-sections A-C below.)

The degree of complication of regulation: the apparent paradox of equity of simple regulation

Regulation must apply at the same time to actors that are merely engaged in simple (economic) processes and to actors engaged in complicated processes. The degree of complication of regulation is determined by three main components.

- First, the degree of complication of concepts and of language;

- Second, the degree of complication of the application of rules, that is, the requirement of (non-)action of the actors (the does and don'ts);

- Third, the degree of complication of the required record-keeping and reporting (for example, for taxation, assets of banks, or compliance with environmental norms).

Each of these three determines the degree of expertise that is required for taking cognisance of the regulation that is relevant to an actor, as well as their compliance. Along with it, the degree of complication and of required expertise also determines the degree to which enterprises and other actors have to hire legal experts for the cognisance of and compliance with regulation (as determining the cognisance costs and the compliance costs). ${ }^{37}$

The alternative to complicated regulation is simply formulated as well as broad regulation. A degree of precision is then substituted by more vagueness and ambiguity, contributing to multi-interpretative regulation. This can only be resolved by leaving the filling in of detail and precision to the courts that is, in case of conflict between actors and regulating authorities over the

37 See also Partlow 2013, pp. 307-8. Where Partlow in this excellent article uses the term complexity I use the term complication. I reserve the term complexity for additional intricacy (see below). Partlow focuses on the legislation and regulation of taxation, from which he also takes his examples. 
interpretation of rules. As courts interpret the law and other regulation, the latter's 'simple' formulations become again complicated, so coming full circle. And as long as the regulation is not adapted into complicated formulations there has to be continuous reference to 'case law' (the courts' interpretation). In the meantime, because court procedures, including appeals, most often take an enormous amount of time (quite apart from their being expensive), 'simple' regulation introduces uncertainty into the regulative constellation. ${ }^{38}$

This is the apparent paradox of equity of regulative complication. On the one hand, equity would require that the reading of regulation not be a matter of high judicial expertise, whilst on the other hand, the interpretation of 'simple' regulation always ends up with high judicial expertise before the courts and such expertise for reading the case law. ${ }^{39}$

Note that especially for taxation, the complication of legislation/regulation increases in degree due to taxation 'instrumentalism', that is, the use of taxation not merely for the collection of money, but also for all kinds of incentives and compensations. ${ }^{40}$ The result is a wide range of often complicated tax subsidies (tax deductions, also called 'tax expenditures'). ${ }^{41}$

Interweaving of regulation

Interweaving of regulation refers to the interconnection between separate regulations at the same level or at different levels. Almost all laws refer to other laws for (at least) definitions and various specifications. In those other laws there are most often again references to still other laws. (See Graph 10.8 in Amplification 10§6-a.) The same applies for delegated regulation. The degree of these cross-references determines the degree of interweaving of regulation. As a consequence a new law, or an amendment of a previous one, induces a series of required amendments of other laws and of delegated regulation (hoping that none is missed).

38 Partlow 2013, pp. 314 and 320-1.

39 Perhaps there might be a way of simplifying the concepts and language of regulation by explaining these in more common language within the law or regulation (it would nevertheless have to be unambiguous common language). However, apart from the problem of the interweaving of regulation (the next sub-section), this will lead to a huge extension of the length of regulation, which also does not contribute to equity because length requires perseverance.

40 Such as for proper environmental behaviour, the hiring of disabled workers, technical innovations, mortgage-type dependent interest deductions, pension-type dependent premium deductions, loss carry back deductions. Much of the instrumentalist objectives could be reached by straight subsidies or by straight prohibitions and injunctions.

See also Partlow 2013, pp. 316-17. 
If one, even very complicated, law were to stand on itself, this would be 'doable'. It is the interweaving of several or a series of complicated laws that multiplies into the complexity of the body of laws and their derived regulation. (See the second block of Figure 10.4.)

In practice the interweaving can be quite desperate, even for a legal expert, when the understanding of one section of a law requires the consultation of a series of other laws and delegated regulations. ${ }^{42}$ In principle at least, this might be overcome by integrating the cross references within each one law. However, its 'price' would be an exponential growth of the quantity of regulation (along with experts each time having to go through lengthy repetitions when they go from one law to the other).

$C$

\section{The fusion of fields of regulation by economic actors}

Additional complexity occurs when the field of operation of an actor is a (new) fusion of fields covered by the existing regulation of fields. (See the second block of Figure 10.4.) Thus it is the actors who dynamically fuse fields. Field fusion occurs, firstly, along with product and especially production process innovations (including, for example, ICT driven innovations). It occurs, secondly, through the integration of formerly separate functions - such as banks' fusing with insurance functions, or car producers' or real estate companies' integrating shadow banking (the point is not different divisions within an enterprise, i.e. conglomeration, but rather full integration). This is not uncommon within technical and organisational dynamic constellations. For both of these types of field fusion, there may be inconsistent rules from different existing regulation fields. Thus the regulation lags behind such changes, though it may eventually catch up - for the time being.

10§6-a Amplification. Interweaving of regulation, an illustration from the UK

In a report about legislation in the UK by the UK Office of the Parliamentary Counsel, it is indicated that:

42 There are field experts. However, experts of 'the' law and other regulation do not exist. Wilhelmina Thomassen, judge in the Supreme Court of the Netherlands, said in a 2011 interview: No one knows even all the laws and each year 29,ooo relevant court decisions are being published (case law relevant) - amongst a total of each year about 1.8 million decisions (in the Netherlands the decisions to population ratio in 2011 was $11 \%$; the 'relevant' decisions to population ratio was $0.2 \%$ ). http://www.nrc.nl/rechtenbestuur/2011/o4/ og/niemand-kent-alle-wetten-en-regels/. 
'new and existing legislation can appear inconsistent. Regulation emanating from different sources sometimes overlaps and commencement can be difficult to follow. Every year, new legislation and amendments result in over 15 , O00 (over 30,000 when considering secondary legislation) legislative effects. The statute book therefore is an ever-evolving network of complex information that expands organically and is extremely difficult to map.'

UK Office of the Parliamentary Counsel 2013, p. 14

The legislative effects are indeed convoluted by their interweaving ('network'). Graph 10.8 visualises an example of this interweaving for one single Act (the Companies, Audit, Investigations and Community Enterprise Act 2004).

GRAPH 10.8 Visualisation of the interweaving of the UK'Companies, Audit, Investigations and Community Enterprise Act 2004' with other earlier and later Acts ${ }^{43}$

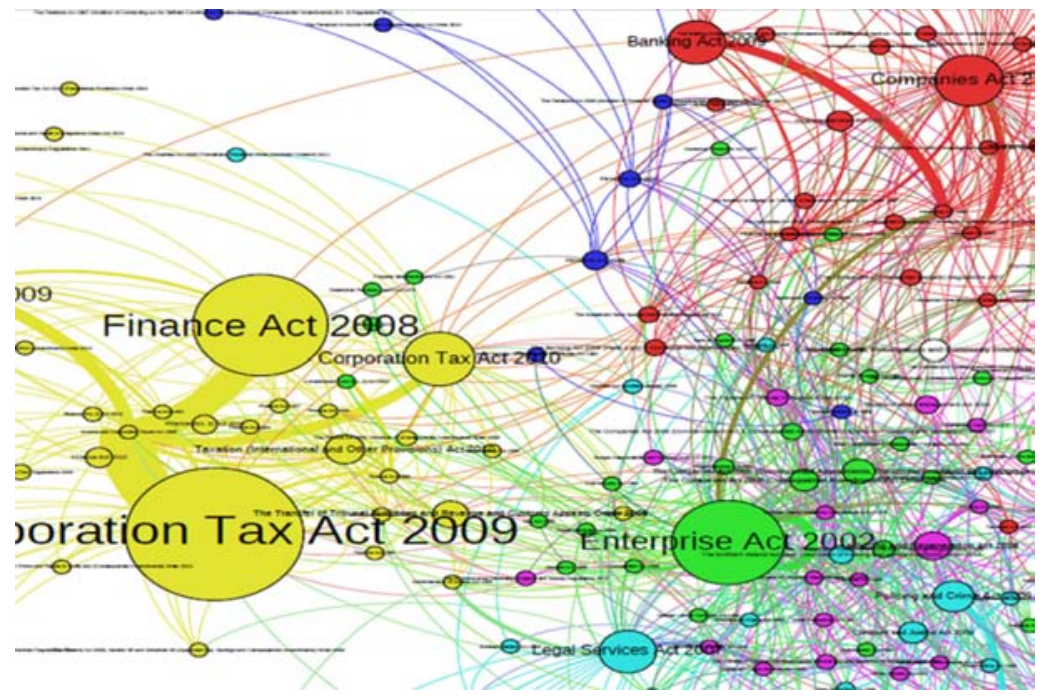

SOURCE: UK OFFICE OF THE PARLIAMENTARY COUNSEL 2013, P. 16

\section{$10 \$ 7$ Change: the tendency to increasing complexity of regulation}

This section presents change of regulation, starting from some state of regulation (and hence a state of complexity of regulation) at one point in time. There are two very different impulses for a change of regulation. Each of these

43 As the Office notes: 'It represents the proportion of the statute book to be taken into consideration when looking at the current in-force state of just that one Act.' 
separately engenders an increasing complexity of regulation. However, in combination these reinforce the increase in complexity. (A and B below, and A and B in the third block of Figure 10.4.)

Increasing complexity as driven by new or re-perceived social-economic problems

Changes of regulation - as driven by new, or re-perceived, social-economic problems - are an ongoing aspect of regulation. For one part these stem from legitimation problems. For another part these stem from changes in the economic structure and product and process innovations, as well as the fusion referred to at the end of the previous section. These affect the 'coverage' and the 'intensity' of regulation, and so the density and quantity of regulation (see the dotted lines in Figure 10.4). The more convoluted the social-economic problems, the more complicated regulations tend to be. (Think of new problems within the financial sector such as those of 'too big to fail', re-perceived problems of the climate and other environmental matters, of new technologies such as those regarding communication and health, and of redesigns of taxation in face of changes in the organisational structure of enterprises.) This results, together with the interweaving, in an increasing complexity of regulation.

Increasing complexity as driven by unintended loopholes in regulation

However, changes of regulation - and especially continuous amendments of existing regulation - are also determined by unintended loopholes in regulation. Their reparation continually increases the complication of single regulations, and in connection with the interweaving of regulations, multiplies into further complexity of regulation.

I define 'loopholes' in laws and/or delegated regulation as rules or stipulations that, unintended by the legislator, permit actors (e.g. enterprises) to achieve goals, or more specifically advantages or benefits, not contemplated by the legislator. ${ }^{44}$

Especially when large financial interests are at stake, enterprises' lawyers and, for taxation, also accountants - painstakingly search the relevant laws and other regulations for ways to take advantage of gaps and ambiguities. By way of borderline (non-)compliance the rules are then tested, and when regulators accuse actors of abuse, perhaps imposing fines, this is often followed by appeal

44 I do not exclude that there are also ambiguities in laws as a result of lobbying pressures (there are even cases in which specific articles of laws derive from lobbyists). Below, however, the focus is on unintended ambiguities. 
procedures before courts. (Note that anticipating all this, regulators themselves also continuously search the law and other regulation for gaps and ambiguities.)

The outcome is a continuous amendment of laws and delegated regulations so as to repair the gaps and ambiguities. 'Because the devices used to take advantage of loopholes are intricate, the amendments addressing loopholes must also be intricate. ${ }^{35}$ This increasing complication - together with the interweaving of increasing complication - results in a tendency to cycles of gaps and ambiguity search, amendments and further complication and complexity. ${ }^{46}$

C

\section{The combined reinforcement of complexity increase}

Whereas increasing complication and complexity stemming from the 'loopholes amendments' (heading B) is a continuous process, any new regulation stemming from new problems (heading A) opens new cycles of loopholes amendments (heading B). The already enormous number of regulations increases (shown in Graph 10.6 for the EU) and the ditto pages of regulation increase (shown in Graph 10.7 for the USA) merely measure the quantity increase, not the complication and complexity increase.

In conclusion. Regulation is inevitable for the reproduction of the capitalist system (Chapters 6-9). However, social-economic changes, and especially the dynamic interaction of the complication and interweaving of regulation, means that an increasing complexity of regulation is inevitable. This is reinforced by the enterprises' profit-driven search for gaps and ambiguities in existing regulation, whence much of the increasing complexity is immanent to this profit drive.

$45 \quad$ Partlow 2013, p. 316.

46 Complication and complexity are not the object of governments, but inevitable. As an anecdote in this respect I might add that when I served as a senator in the parliament of the Netherlands and when in 2015 a complicated seven-page amendment to the corporate taxation law was proposed (with direct repercussions for four other taxation laws) requiring an explanatory memorandum of no less than $5^{2}$ pages - I asked the secretary of state in official written communication if he himself considered this a proposal that would result in a further complexity of the corporate taxation law. His written answer was (in brief) that 'the complexity increase is undeniable' but that, in the cabinet's opinion, 'this complexity increase is just about acceptable' (Government of the Netherlands, Secretary of State for Finance 2015, p. 22). I retorted by asking whether the cabinet ever proposes laws that it considers just not acceptable. 


\section{Division 3. The capitalist state's hard core and its manifestation in expenditure as quantitatively dominated by social security transfers}

The previous division presented the reach of the capitalist state as manifested in the character of regulation. The current division presents the manifestation of the state in the development of its expenditure. All of the main expenditure categories will be briefly reviewed. However, the focus will be on the development of the quantitatively dominant category of social security expenditures and its interconnection with public education and the communications part of infrastructure - in the division's last section $\left(10 \S_{12}\right)$.

\section{$10 \S 8$ The manifestation of the state: the actors' experience of the state's existence}

- The hard core of the capitalist state

The existence of the state is manifested in processes of legislation, public security and the upholding of the law. As indicated in $6 \$ 2-6 \S_{3}$, the existence of the capitalist economy requires that these processes regard primarily state-granted legal rights of:

(a) claims of entitlement to private property in the earth;

(b) claims of entitlement to private property in means of production other than for production by the claimant;

(c) claims of entitlement to employ labour as combined with the appropriation of the surplus-value produced by that labour;

(d) claims of entitlement to existence (in the sense of 'allowance').

In granting particularly these claims as legal rights, the state is identified as the capitalist state $(6 \S 3)$. In this division this constellation, together with the other moments of the exposition in Chapter 6, will be denoted as the capitalist state's 'hard core' (HC).

- The hidden hand of the capitalist state

For many people the economic rights that the state grants ( $\mathrm{a}-\mathrm{c}$ above), and the legislation about them, are not part of their conscious experience. For them 'the state' is an abstract entity. They are aware of the state as persons staffing the coming and going governments, associated with 'them' in the capital city, with 'them' in the municipality's building, and with the police or other authorities rapping people on the knuckles.

At the same time they may feel, or know, that 'the state' consolidates a skewed 'economic' distribution of power, property, income and esteem. In fact they experience the granted legal rights (a)-(d) in the form and at the site of the actually claimed property and employment entitlements, that is, their 
everyday workplace - if they have paid work. They also experience it in the level of their pay cheque at the end of the week or month - one that, if they are lucky, allows them to live a life above the poverty line, or a comfortable one. Thus in this everyday experience, the hard core of the state is a hidden hand'.

- The experience of the capitalist state in terms of its expenditure

Most people experience the reach of the state predominantly in its expenditure and the allocation thereof. That is, in the supervision of the safety of production and products (10§9), in public education (10§10), in infrastructure (10§11), in the public goods part of social security (especially health) and in the other components of social security $(10 \S 12)$.

10§8-a Amplification. Notes on the synthetic overview of state

expenditure in the OECD-21, 1870-2015, in the amplifications of the current division

The amplifications in this division present a most brief synthetic overview of the components of state expenditure for the average of the current OECD-21 in the period of full-fledged capitalism hitherto (1870-2015). Most of the space will be devoted to the social security expenditure (10§12), which, as we will see, appears as one of the two main 'inevitable vulnerabilities' of the capitalist system (the other one being the increasing complexity of regulation).

The overview in the amplifications is merely one in terms of graphs of the decade development since 1870 , the idea is that in each one single decade (e.g. 1920) the state is manifest in its expenditure on the Hard Core (the hidden hand) and in the other, experienced, expenditure. Many of the amplifications of Chapters 7-9 anticipated on the synthesis in the current division. As much as in those amplifications, the current ones refer to an average of the hitherto 'strong' capitalist countries as empirically exemplified in the average of the current OECD-21 countries (see Appendix 6A, section 6A-1).

The overview will - to the extent that empirical statistics are available - follow the order of the eight regulative frameworks presented in Chapters 6-7 and 9. The Hard Core frameworks (Chapter 6) have a special status regarding their necessary intensity. The other frameworks are necessary, whereas their regulative intensity and the degree of expenditure may vary over time. In fact, however, to a large extent these seem to have a ratchet character: substantial expenditure decreases are rare. ${ }^{47}$ Capitalism is a dynamic system that may generate

47 Infrastructure is an exception (with a decrease in \% of GDP from $3.2 \%$ in 1970 to $1.9 \%$ in 2015). See $10 \$ 11$. 
outcomes threatening its continued existence, thence requiring new necessary action of the state.

For all of the categories that were presented in the eight regulative frameworks of Chapters 6-7 and 9, empirical statistics are available from 1995. In this division, however, state expenditure is put in the long-term perspective of 1870-2015, for which the detailed data are most often lacking. This implies a reliance on compromises and sometimes rough estimates. These are set out in Appendix 10.A, under 10§8, see especially Table 10.13.

\section{$10 \S 9$ The necessary state expenditure on the Hard Core and Inspectorates, and the contingent military and interest expenditure}

The term Hard Core was explained in $10 \S 8$. 'Inspectorates' regard those of production (working conditions and the minimum wage), of products, and of the environment.

The military expenditure and interest expenditure of the state are taken as contingent.

10§9-a Amplification. State expenditure on the Hard Core, Inspectorates, and the contingent military and interest expenditure of the OECD-21, 1870-2015

As explained in Appendix 10.A under 10§9-a, for throughout the 1870-2015 period I pragmatically adopt constant expenditure figures for the Hard Core and Inspectorates (3.3\% and $0.1 \%$ of GDP, as an estimate derived from actual 1995-2015 data). This means that these expenditures absolutely increase (or decrease) with GDP.

Graph 10.9 is the first one of a series of four graphs on the OECD-21 state expenditure in the period $1870-2015$. This is an introductory graph, which is not interesting in terms of the constant reference figures for the Hard Core and the Inspectorates (3.3\% and $0.1 \%)$. The main point of this graph is the incorporation of the two contingent expenditures referred to: military and interest expenditures. It can be seen that these two contribute considerably to the relative decline (in percentage of GDP) of total state expenditure between 1990 and 200o. (A separate graph for military expenditure is included in Appendix 10.A under $10 \$ 9$. Military expenditure already steadily declines after 196o; sufficient data for 1950 are lacking. The same location provides a separate graph for (the rather volatile) interest expenditure.) 
GRAPH 10.9 Total state expenditure (general government) and expenditure on the Hard Core, as well as on contingent military and interest expenditure, 1870-2015, in \% of GDP; averages of up to 21 current oECD countries ${ }^{\dagger}$

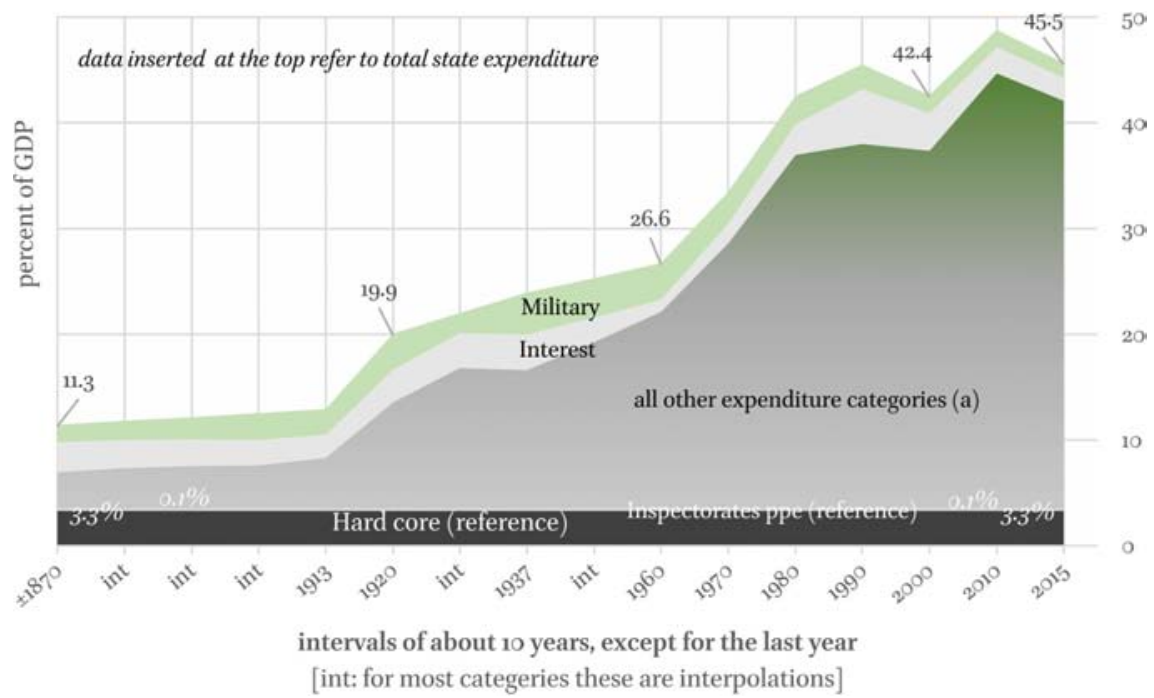

$\dagger \quad$ Inspectorates ppe $=$ Inspectorates of production, of products, and of the environment. DATA SOURCES: For total expenditure, see Graph 8.2. For military expenditure: 1870-1980 (mainly Sabaté 2013); 1990-2015 (World Bank database, details are in Appendix 10.A under 10§9). For interest expenditure: 1870-1937 (Tanzi and Schuknecht 2000); 1960-current (OECD Economic Outlook database, details are in Appendix 10.A under 10§9)

\section{$10 \$ 10$ Expenditure on the monetary and labour-capacity frameworks}

The primary conditions furthering the accumulation of capital regard the monetary framework $\left({ }_{7} \mathrm{D}_{2}\right)$ and the labour-capacity framework $\left.{ }_{7} \mathrm{D}_{3}\right)$. Net state expenditure on the monetary framework (supervision of banks and other financial institutions) can be neglected. The main part is carried out by the central bank, which on average makes profits that are distributed as dividends to the state. ${ }^{48}$

The main expenditure on labour-capacity regards public education.

10§10-a Amplification. The labour-capacity expenditure of the OECD-21 The expenditure on this category will be shown later on in Graph 10.10. Regarding the labour-capacity framework, the expenditures associated with temporary unemployment and labour population growth (child benefits), will

48 This distribution may not be the case in all countries. 
pragmatically be subsumed under the social security transfers. Equally for pragmatic reasons, the expenditure on minimum wage 'inspectorates' (and commissions) has been subsumed under Inspectorates (see Appendix 10.A, Table 10.13).

This leaves the substantial state expenditure on public education and its increase from 1870 to 2015 (see also Graph 7.6). Its content and the degree of expenditure may generally change along with technical change. As shown in Graph 7.5, the average of the total years of education increased between 1870 and 2010 from 3.5 to 12 years.

\section{$10 \$ 11$ Expenditure on the infrastructural framework}

As with education, state expenditure on infrastructure may generally change along with technical change (cf. $\left.7 \mathrm{D}_{4}\right)$. Think of the introduction of new energy carriers (e.g. electricity), transport (e.g. rail) or communications (telephone, ICT), which require new networks. (These and other technical changes also require extensions and changes of public education for at least the middle and higher levels.) Regarding state expenditure proper, it should be noted that quite some infrastructural provisions may be carried out by state-owned enterprises or by (for that purpose regulated) private enterprises - perhaps via concessions or licenses. In such cases these provisions are not shown in the figures as state expenditures but rather, conversely, as state revenues (dividends, royalties).

10§11-a Infrastructural expenditure of the OECD-21

The last remark in $10 \S 11$ is relevant for the interpretation of the relative decline of infrastructural expenditure after 1970. State expenditure on infrastructure is approximated by a factor 0.575 of state gross investment (Graph 7.5 in $7 \S 15$ and Graph 7.5-a in Appendix 7.A).

Graph 10.10 shows the state expenditure on education and infrastructure in the total expenditure context.

As measured in percentage of GDP, expenditure on education rose continuously from $0.6 \%$ in 1870 to $4.8 \%$ in 1980 , and after that year somewhat fluctuated, though with still an upward trend (5.7\% in 2014). The expenditure on infrastructure moved from $1.2 \%$ in 1870 to a top of $3.2 \%$ in 1970 and then gradually decreased to a level of $1.9 \%$ in 2015 .

Regarding the labour productivity increases that can be reached for the production of these two categories themselves (that is, apart from their labour productivity effect for other sectors), it is noted that these are quite different (see Amplification 10§11-b on 'Baumol's cost disease'). 
GRAPH 10.10 Total state expenditure (general government) and the expenditure on education and infrastructure, 1870-2015, in \% of GDP; averages of up to 21 current $O E C D$ countries

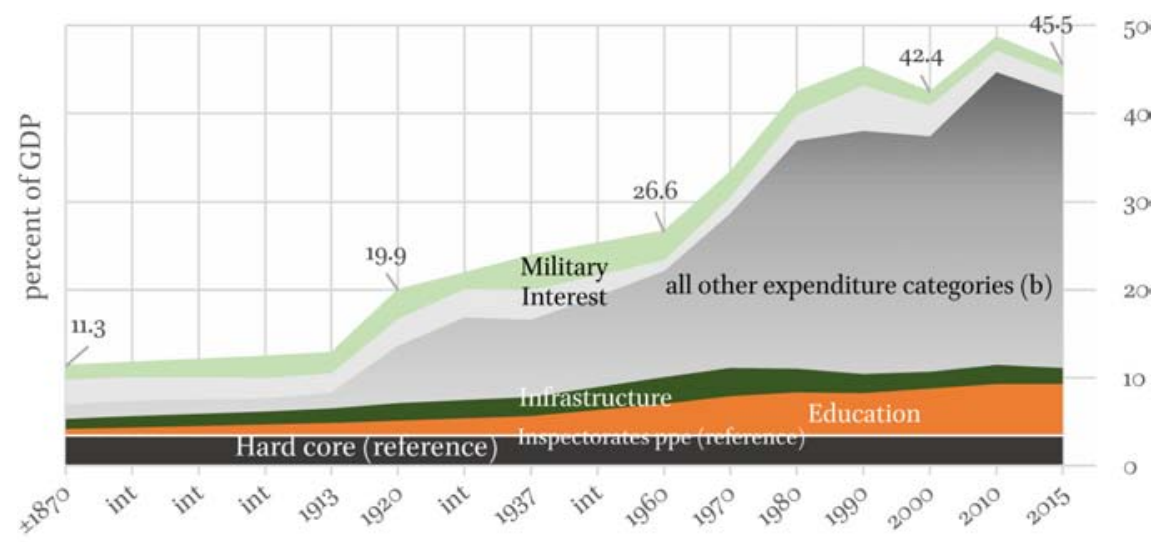

intervals of about 10 years, except for the last year

[int: for most categeries these are interpolations]

Education 1920 is interpolated and $2015=2014$

DATA SOURCES: for education see Graph 7.6; for infrastructure see Graphs 7.7 and 7.7a; for the other categories see Graph 10.9

10§11-b Amplification. Diverging labour productivity changes: 'Baumol's cost disease'

Labour productivity increases that can be reached for the production of infrastructure and for education are quite different. Think of road construction and of a class in economics now and 10o years ago (for the latter the main difference is the use of PowerPoint instead of chalk and a blackboard). Baumol's theorem of 'cost disease' refers to the phenomenon of structurally enduring productivity differences between particular economic sectors. The theorem originated with a paper by Baumol and Bowen (1965), which illustrated differences in labour productivity change with the example of a symphony orchestra whose productivity for performances today is pretty much the same today as in 1870 . In various different degrees, similar labour productivity obstacles apply for many state expenditure categories, such as the Hard Core processes, Inspectorates, Education and the care part of the Health sector. 


\section{$10 \$ 12$ Expenditure on social security as connected with the development of the accumulation of capital}

- Social security transfers

In the terminology of the current division, the legitimation for the state's 'hard core' may require 'the price' of considerable generalised social security transfers (henceforth SST). The expenditure categories presented so far in this division are in a way straightforward: the bare accumulation of capital requires these. The sst are necessary to the extent that the legitimation of the state requires these, and so have 'become necessary' for the existence of the state and hence the capitalist system. ${ }^{49}$

- Three discourses of the appreciation of $s s T$

In the appreciation of the development of the SST there are three discourses. The first one applauds ss T from a moral or ethical perspective (assistance to the poor, although generalised ssT goes beyond that). The second one complains about the SST's lack of 'market conformity' or 'economic efficiency' (much of the instrumentalist public choice approaches). The third discourse conceives of SST as the failure of a production and market system that is incapable of providing a major part of the population with the opportunities to make a decent and equitable living of their own, including provisions for their old age.

In the state's argumentation for a particular degree of ssT being in the putative 'general interest' $(6 \S 6)$, it has to take account of each of these discourses. Regarding the reproduction of the capitalist system, however, it is in the end not these discourses that count, but rather the compliance of the vast majority. ${ }^{50}$

The current level of ssT is one thing, another is its future level. Each time in the history of full-fledged capitalism it was considered that 'today' we have reached a level of SST that for the future sufficiently safeguards this component of the state's (hence the capitalist system's) legitimation. In hindsight erroneously so. In 196o, 198 o or 2000 there was such a 'today'. Even if erroneous in hindsight, nevertheless SST as a percent of GDP cannot feasibly increase forever. (The end point would be reached when $50 \%$ of the aggregate dis-

49 See also the General methodological Appendix, A§13, point 5 , on the notion of 'becoming necessary'.

$5^{\circ}$ I am not arguing that SST is the only component of the state's legitimation. However, it is a predominant one within the complex of legitimation determinants. After $6 \mathrm{D}_{3}$ (when introducing the state's legitimation requirement in general terms in $6 \S_{4}$ and $6 \S 5$ ) I explicitly referred to legitimation in the context of: (1) the introduction of the state's furthering of the conditions for the accumulation of capital and economic growth $\left(7 \S 3\right.$ of $\left.7 \mathrm{D}_{1}\right) ;(2)$ the social security framework $\left(7 \mathrm{D}_{5}\right)$; (3) various institutional assignations and delegations (7D6-7 $\left.\mathrm{D}_{7}\right)$; (4) the forms and designs of taxation $\left(8 \S 11\right.$ of $\left.8 \mathrm{D}_{5}\right)$; and $(5)$ the framework of competition $(9 \mathrm{D} 1-9 \mathrm{D} 2)$. 
posable income of households consists of transferred income. Depending on the exact distribution of this $50 \%$, this would mean that the skewedness in the distribution of disposable income would fade. I mention this only as a brief 'thought experiment' that has little to do with the exposition of the actual capitalist system.)

\section{- Accumulation of capital and the trend in SsT}

The state's hard core legislation allows enterprises and their owners to monopolise the property of the earth and other means of production, and to appropriate the surplus-value produced by labour (6D2). One main result is a skewed distribution of income - and, derived from it, of wealth $\left(8 \mathrm{D}_{5}\right)$ - which is extenuated by ssT. Along with it, SsT is a dominant component of the vast-majoritycompliance that the state's existence requires for its legitimation.

In re-distributional terms 'generalised SsT' - rather than 'mere' assistance to the poor - tends to positively affect roughly the bottom $50 \%$ of the income distribution (Table 8.17). ${ }^{51}$

Trends in the distribution of income and in SsT do not stand on their own. Widespread information (knowledge and its communication) about the distribution of income is a key catalyst for SST. This information correlates, on the one hand, with public education - especially also its distribution (cf. Graph $7 \cdot 5$ ) - and, on the other, with means of communication. These two, again, correlate with the development of the macroeconomic accumulation of capital. Thus, in brief, the capital accumulation requirements of increasing public education and of the communication parts of infrastructure $(7 \S 14 ; 7 \S 15 ; 10 \S 10$; $10 \S 11)$ engender ssт. Thus, even briefer, the state of the accumulation of capital determines the state of ssT. This is a major destiny of the capitalist system.

Increasing SST as a percentage of GDP is thus generally driven by the articulation of two factors: on the one hand, the state's vast-majority-legitimation requirement, and, on the other, the degree of widespread information as associated with the accumulation of capital. It is the thus determined information that catalyses the necessity for the state to raise the SST.

Given that SsT tends to positively affect roughly the bottom $50 \%$ of the income distribution, a raising ssT thus primarily contributes to the compliance of the bottom. However, the question is where the burden for the increasing ssT is going to fall. (Effectively this question is less urgent to the extent that the average per capita growth rate structurally booms. The deciles mean-income lays

51 I derive this from data about recent years for OECD countries. Perhaps this borderline has gradually moved from a lower one to the current one. For many non-OECD countries the borderline might perhaps (still) lay at $20 \%$ to $40 \%$. For countries with (yet) nongeneralised SST, assistance to the poor may regard the bottom $20 \%$. 
well above the median income. $)^{52}$ If the burden of the increasing SsT initially is going to fall on the upper-middle classes (income deciles D6-D9), the state risks a fading legitimation in this echelon. ${ }^{53}$ If it is going to fall on the upper class (Dio), members of this class may wonder about the further rationale of the capitalist system for them.

There seems to be no obvious way to evade this dilemma.

10§12-a Amplification. Social security expenditure of the OECD-21, 1870-2015

Graph 10.11 shows the OECD-21 state expenditure on SST in the context of total state expenditure from $1870-2015 .{ }^{54}$ As for similar graphs before, this graph shows a per decade summary of the manifestation of the reach of the state in terms of its expenditure.

\section{GRAPH 10.11 Total state expenditure (general government) and state}

expenditure on social security, 1870-2015, in \% of GDP; averages of up to 21 current $O E C D$ countries ${ }^{\dagger}$

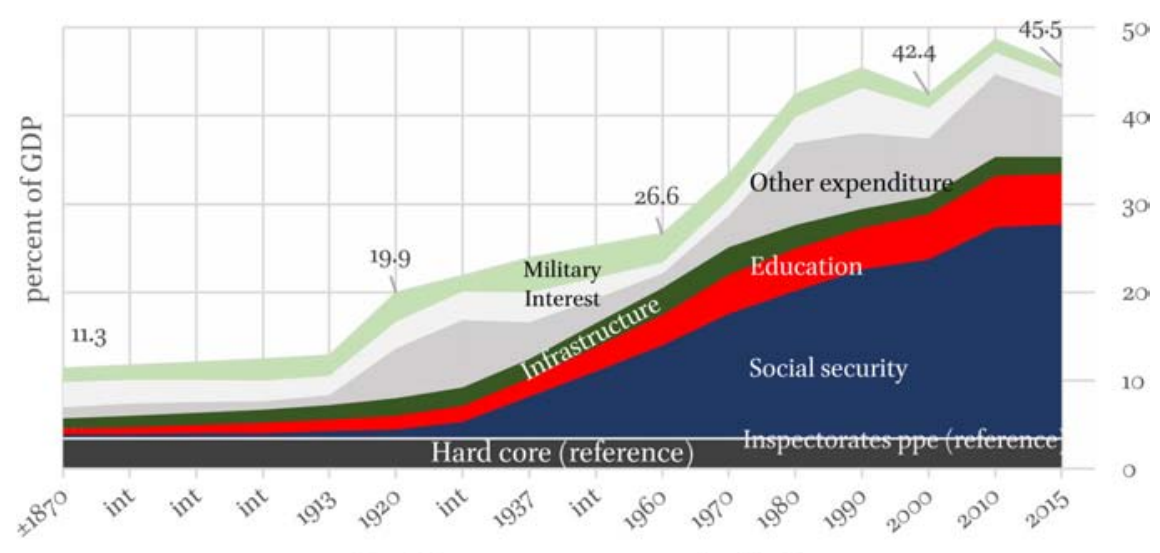

intervals of about 10 years, except for the last year

[int: for most categeries these are interpolations]

$\dagger$ Social security $1870=188$ o. SST interpolations are for 1937 and 1950 only DATA SOURCES: for social security see Graph 7.10; for the other categories see Graph 10.10

$5^{2} \quad$ For OECD-21countries it lays in 2015 around decile 7.

53 See the one but last footnote. At a lower borderline of generalised ssT, this may stretch to, for example, D4-D9.

54 Including temporary unemployment benefits and child benefits - see Appendix 10.A under $10 \S 12$ for details. 
Graph 10.11 shows that in 1920 the average of the SST amounted to $1 \%$ of GDP, increasing to $24 \%$ in 2015. Total state expenditures in this period increased from $20 \%$ to $45 \%$ of GDP. (See also Graph 7.10, which is somewhat more detailed.) From 1930-90 we see a rather continuous and stable upward trend in SsT. After 1990 the increase bends off, but at least until 2015 it kept increasing (very moderately after 2010). ${ }^{55}$

\section{$10 \S 13$ 'Other state expenditure': contingent expenditure and required expenditure on especially 'too big to fail' banks}

Under 'other state expenditure' I classify the so far $(10 \$ 9-10 \S 12)$ not mentioned state expenditures. I subsume these under the following two categories.

- Subsidies and other direct assistance for enterprises

Most of these can be considered as contingent. However, the direct assistance also includes assistance related to 'too big to fail banks' which, as an expenditure, is definitely necessary given the phenomenon (cf. $9 \S 6$ ).

\section{- General amenities}

This is a rather heterogeneous category, which includes mainly expenditure on culture, religion, community, recreation, foreign aid, and research and development of a general character. Much of the last one is necessary $(7 \S 16)$. For the others I refrain from scrutinising their (non-)contingent character, also because their degrees of contingency may evolve over time. (Expenditure on religion, for example, may at certain times and in certain places serve an indispensable function, which at other times fades.)

55 Although there are quantitative level differences for different OECD-21 countries, these have, with some fluctuation, all moved in the same direction.

SST of current OECD-21 countries as \% of GDP, 1880-2015: SST range

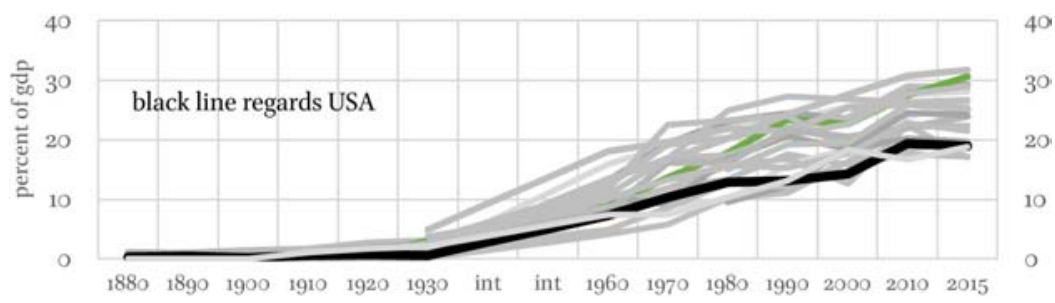

Take the example of the USA. In 1920 its SST was a fraction 0.81 of the OECD-21 average. In 1980 the fraction was 0.77 and in 2015 it was 0.78 , which is a rather stable deviation from the average. Thus its SST moved at about the same pace as the OECD-21 average. Including the USA there was a stable increase in nine countries. In eight countries there were slight fluctuations, and in the remaining four there were some heavy fluctuations (Ireland, the Netherlands, New Zealand and Norway). 
10§13-a Amplification. Contingent and required 'other expenditure' in the OECD-21, 1995-2015

Graph 10.12 provides the movement of the two main categories of 'other expenditure' mentioned in $10 \S 13 .{ }^{56}$ (Graph 10.12-b, in Appendix 10.A, under 10 13 , is a more detailed one; Graph 10.12-a provides a subdivision for the 'subsidies and other direct assistance for enterprises'.) Internationally more or less homogeneous data for these expenditures are only available for the years 1995-2015. Their total stood at a relative low around 196 o (in fact 1.6\% of GDP - not much above the $1870-1913$ levels). In 2015 it had increased to $6.8 \%$ of GDP, though with fluctuations in between.

It appears that most of the fluctuation in total state expenditure from 19902015 can be traced to the 'other direct assistance for enterprises' and to interest expenditure.

GRAPH 10.12 Total state expenditure (general government) and state expenditure on 'general amenities' and on 'subsidies and other direct assistance for enterprises, 1870-2015, in \% of GDP; averages of up to 21 current $O E C D$ countries

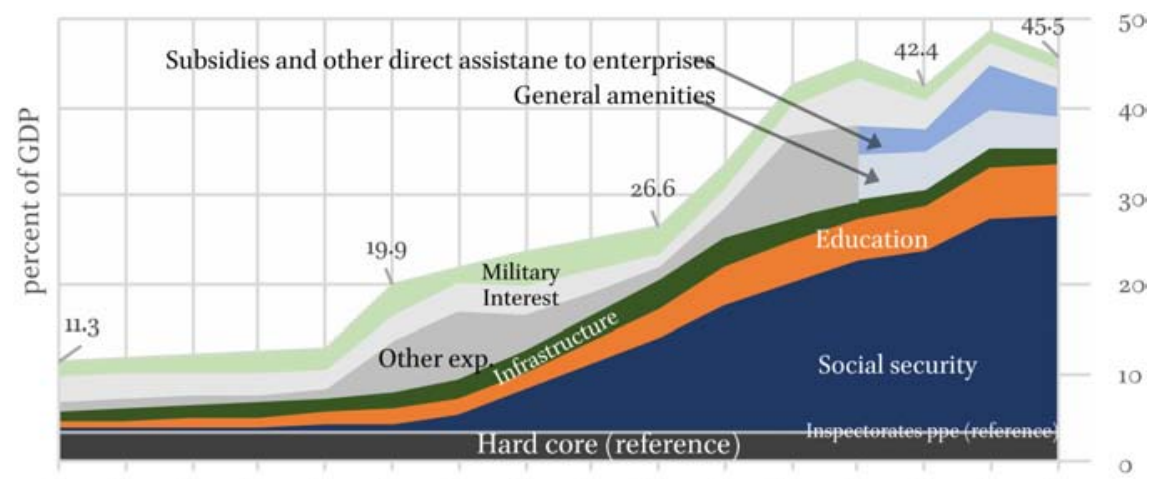

intervals of about 10 years, except for the last year

[int: for most categeries these are interpolations]

DATA SOURCES: for General amenities and Subsidies and other direct assistance for enterprises: OECD COFOG data (for these two subcategories 1990=1995) - see Appendix 10.A under 10 $\$ 13$ for further details. For the other categories see Graph 10.11

56 The two result from a regrouping the OECD's COFOG categories - for details about this see Appendix 10.A under $10 \S 13$. 


\section{Division 4. The vulnerabilities of the capitalist state's reach}

This is a brief single section division that builds on the threads of the exposition in the previous two divisions. Whereas Chapters $6-8$ successively presented the conditions of existence of the state vis-à-vis the capitalist economy, this final division detects the flaws, the loose ends in these conditions of existence. In other words, it detects the potential impediments to the continued reproduction of the capitalist system.

\section{$10 \$ 14$ Vulnerabilities and impossible necessities}

\section{- The vulnerability of increasing complexity of regulation}

As indicated in Division 2, the capitalist system has been and is being sustained not just by regulation, but rather by a continuously increasing amount of complicated as well as complex regulation. There is no evidence that this trend could be countered. This means that each year a 'free market economy' will become further removed from the economics textbook phantom ('phantom' because it never existed anyway). ${ }^{57}$

- 'Too big to fail': the vulnerability of the banking constellation - countered by capping the accumulation of single capitals?

The last section of Division 3 coloured a main part of the state's 'other expenditure' with the somewhat anonymous 'other assistance to enterprises'. Behind it lurks, what will be for the future, rather unpredictable state expenditure on 'too big to fail' banks ( $7 \S 9$ and $9 \S 6)$. Within the history of capitalism this is a new phenomenon, one unprecedented in the proportions of its system-wide consequences. It might seem that the solution - a cap on the size of banks - is rather obvious. However, capping capitalist success - success that, by all prevailing standards, is not illegal - would seem to be alien to the capitalist logic and to the capitalist state's hard core. (Moreover, concretising such a cap in watertight legislation will be complicated.) Regarding banks, the solution - for the time being - is that of tighter, discriminating regulation of the too big to fail banks (those that pose a 'systemic risk') as opposed to the regulation of the not so big banks (see 9\$6). In fact this is a (yet moderate) indirect regulative movement towards putting a cap on the size of big banks. ${ }^{58}$

57 Recall from $10 \S 5^{-a}$ that, counting merely the size (numbers of pages), the number of pages of the USA Code of federal regulations stood at 22,877 in 196o and 178,277 in 2015. Their average rate of growth was $4.9 \%$ per year, which was 1.5 times faster than the annual GDP growth. Recall that at the same rate of growth, the number of pages of regulation will have increased to one million in 205 o.

$5^{8}$ Although this is what it does, a moderate indirect cap (as in Basel Committee on Banking 


\section{- Over-accumulation of capital: the unresolved environment restoration}

Protection of the environment (including the climate) is a systematically highlevel requirement, albeit an apparently 'elastic' one (6\$14). Whereas this is a continuous and structural requirement, its aberrations are cyclically highlighted. Chapter 5 showed the manifestation of the capitalist economy in the cyclical accumulation, over-accumulation and destruction of capital. I focus on this because it is key to the dynamic of the capitalist system: its way to get out of the inevitable economic crises of capitalism. Along with it we have a recurrent destruction of the earth's resources. We also see the despair of recurrent super-unemployment, which, in terms of family lives, extends further than losing income. State expenditure, as we have seen in $10 \mathrm{D} 1$, does not annihilate this process, but rather mitigates it, which is a blessing in disguise.

Given the social security transfers (yet especially in the capitalistically developed countries), it would seem that the capitalist system generates a mode of coping with the unemployment side of the cyclical over-accumulation of capital. It has not done similar for its environmental side (at least at the time of writing). However, when a sustainable environment withers away, it is not just that capitalism will also come to an end; so too will humankind.

This is the 'tragedy' of the private property of the earth associated with the structural accumulation and the cyclical over-accumulation of capital. Nevertheless the capitalist system could in principle cope with it at the 'price' of a further increase in the size of complicated and complexity-raising regulation an unprecedented further increase in such regulation. By now all the even slightly enlightened top management of enterprises knows that the earth is vulnerable. Nevertheless, the motivational structure of profit-seeking, engrained within the capitalist system, leads actors to test and retest the loopholes of the law, seeking what they regard as a better way for enterprises to share the burdens of the tragedy $(10 \S 7$ of $10 \mathrm{D} 1) .{ }^{59}$

- Vast majority legitimation: the vulnerability of increasing social security transfers

We have seen in $1_{0} \mathrm{D}_{3}\left(10 \S_{12}\right)$ that widespread information (knowledge and its communication) about the distribution of income is a key catalyst for SST.

Supervision, 2014) may not do away with too big to fail banks. It may take another banking crisis before the indirect cap becomes sufficiently tight so as to force the too big banks to partition into smaller entities in face of their rate of profit.

59 It is one thing to make a target agreement (as in the 2015 Paris Agreement on climate change); it is another to carry it out in practice. (A major drawback of the 2015 Paris Agreement is that it includes no instruments through which to enforce the reaching of its targets.) 
Increasing SST as a percentage of GDP is driven by a complex of, on the one hand, the state's requirement of a vast-majority-legitimation, and, on the other, the degree of widespread information as associated with the development of the accumulation of capital. The state expenditure on public education that is necessary for the accumulation of capital forms a core element within this complex.

Whereas the thus catalysed increasing SST as a percentage of GDP is necessary for the vast-majority-legitimation of the state (this regards the large bottom of the income distribution), the bearing of its burden (by the large upper part of the distribution) implies that the increases' fading off is equally necessary for the state's vast-majority-legitimation.

\section{- Impossible necessities}

Parts One and Two of this book set out an exposition of the conditions of existence of capitalism's 'dissociated outward bifurcation into households and privately owned enterprises'. Throughout this book, so far, I have avoided using the term 'contradiction' (see the last addendum of ${ }_{1} \mathrm{D}_{1}$ ). In the current context a contradiction is a constellation that is at the same time necessary and impossible. For two of the four vulnerabilities of the state's reach, presented above, capitalism is moving toward such impossibilities that stand on their own: the increasing size and complexity of regulation and the increasing social security transfers. The other two major vulnerabilities might perhaps reduce to a further increasing size and complexity of regulation - especially for the climate and natural resources that would be better for the future of humanity.

10§14-a Explication. Further on the main vulnerabilities

I have not argued that capitalism is at, or near to, the point of collapse. I argue that even if the vulnerabilities of the environment and of too big to fail entities could be mitigated or perhaps resolved, the capitalist system that existed from 1870 to the present is moving toward being an impossible constellation.

This is based on the state's legitimation requirement (and because capitalism cannot exist without the capitalist state, this is a system requirement). I have also not posited that a representative democracy is necessary for capitalism (alas). However, I posited that the legitimation of the capitalist state in the vast majority of the population is necessary $(7 \S 23)$. Ultimately this requirement is connected with the material limits of the state's legalised violence on a large scale (6\$18). (However, I have not argued that such large-scale violence cannot exist for a 'relatively' short period - of perhaps one or even two decades - as history has shown.) 


\section{Summary and conclusions}

This chapter set out three key manifestations of the state, which together determine its reach.

The first of these manifestations applies to the cyclical movement of capital accumulation (which so is the sequel of Chapter 5). State expenditure mitigates the amplitude of 'regular' economic cycles. The degree of this automatic stabilising effect depends on the structural size of state expenditure in comparison with private expenditure. This is different for the 'irregular' economic downturns triggered by financial crises and bank failures. Then the mere state expenditure floor may not be a sufficient base for getting to a recovery via 'normal' restructuring destruction of capital. Reproduction of the capitalist system then requires substantial discretionary state policy. (Division 1.)

The second manifestation regards the character of the state's regulation of the capitalist economy. The mere quantity of regulation in force increases over time, as driven by new, or re-perceived, social-economic problems. For one part these stem from legitimation problems. For another part these stem from changes in the economic structure and product and process innovations, including process fusions. These affect the 'coverage' and the 'intensity' of regulation, and so the density and quantity of regulation. The more convoluted the social-economic problems, the more complicated regulations tend to be. This results, together with the interweaving of regulations, in an increasing complexity of regulation.

However, changes of regulation are also prominently determined by 'unintended' loopholes in regulation, that is, gaps and ambiguities - as tested by way of profit-driven borderline (non-)compliance. The legislative and other regulative reparation of these loopholes by amendments of the regulation increases the complication of single regulations, and in connection with the interweaving of regulations, multiplies into further complexity of regulation. This results in inevitable continuous cycles of finding loopholes, making amendments, and further complication and complexity. (Division 2.)

The third manifestation regards the expenditure of the state. For many people the hard core of the capitalist state - in brief the property and exploitation rights that it grants and the legislation related to this - is not part of their conscious experience. The majority of employed actors experience the state primarily indirectly via their everyday workplace, whence the state's hard core operates as a 'hidden hand'. For most people the state's reach is instead directly manifested in the materialisation of its expenditure, especially in the supervision of the safety of production and products, in public education, in infrastructure, and in social security provisions, including health provisions. 
Among the main expenditure categories of the state, spending on social security transfers (SST) is the quantitatively dominant category and it tends to increase over time. SST is a major factor through which the state gains the vast-majority-legitimation that it requires (that is, legitimation for ultimately the hard core property and exploitation rights that the state grants). However, trends in the SST do not stand independently. Widespread information (knowledge and its communication) about the distribution of income is a key catalyst for SST. This information correlates, on the one hand, with public education and, on the other, with means of communication. These two, again, correlate with the development of the macroeconomic accumulation of capital. Thus the capital accumulation requirements of increasing public education and of the communication parts of infrastructure engender SST.

Whereas the thus catalysed increasing SST as a percentage of GDP is necessary for the vast-majority-legitimation of the state (this regards the large bottom of the income distribution), the bearing of its burden (by the large upper part of the distribution) implies that the increases' fading off is equally necessary for the state's vast-majority-legitimation. (Division 3.)

The final Division 4 draws together some threads of Divisions 2 and 3 under the title of 'the vulnerabilities of the capitalist state's reach'. This division sets out the four main vulnerabilities of the reach of the capitalist state and that, as such, comprise potential impediments to the continued reproduction of the capitalist system. The first one is the inevitably increasing amount and complexity of regulation. Thus the so-called 'free market economy' will become unlimitedly further constrained by the steering of the capitalist state. The second vulnerability regards the 'too big to fail' entities - especially banks. This vulnerability can perhaps be resolved by rounds of complex regulation, but for the time being this is insecure. The third vulnerability relates to the deterioration of the environment. This is in fact the most far-reaching one. But perhaps a recuperation is possible by, again, rounds of complex regulation - rounds that will have to be far more stringent than the regulation in prospect (at the time of writing). The fourth vulnerability regards the required state expenditure on social security transfers. Whereas increasing transfers as a percentage of GDP are necessary for the vast-majority-legitimation of the state, the increases' fading off is equally necessary for the state's vast-majority-legitimation.

For the continued reproduction of the capitalist system, the state inevitably has to deal with these vulnerabilities. The second and third vulnerabilities are 'imaginably' resolvable. However, for the first and last ones, the capitalist system is moving toward a constellation of, what I called, 'necessities that are impossible'. 


\section{Appendix 10.A. Data and data sources of the graphs in chapter 10}

General note: For all years (1870 to 2015) I have used the maximum amount of information that my sources provide for the OECD-21 countries.

\section{Re $\mathrm{IOD}_{3}$ Limitations of empirical-statistical expenditure categories, and how these have been accounted for}

For all of the categories that were presented in the eight regulative frameworks of Chapters 6-7 and 9, empirical statistics are available from 1995. In $1_{3} D_{3}$, however, state expenditure is put in the long-term perspective of 1870-2015, for which the detailed data are most often lacking. This implies a reliance on compromises and sometimes rough estimates. The rough estimates regard especially the Chapter 1 categories. One minor compromise pertains to the labour capacity and social security frameworks. Table 10.13 summarises how the lack of data for pre-1995 has been accounted for.

TABLE 10.13 The regulative frameworks and empirical-statistical expenditure categories for Division 3

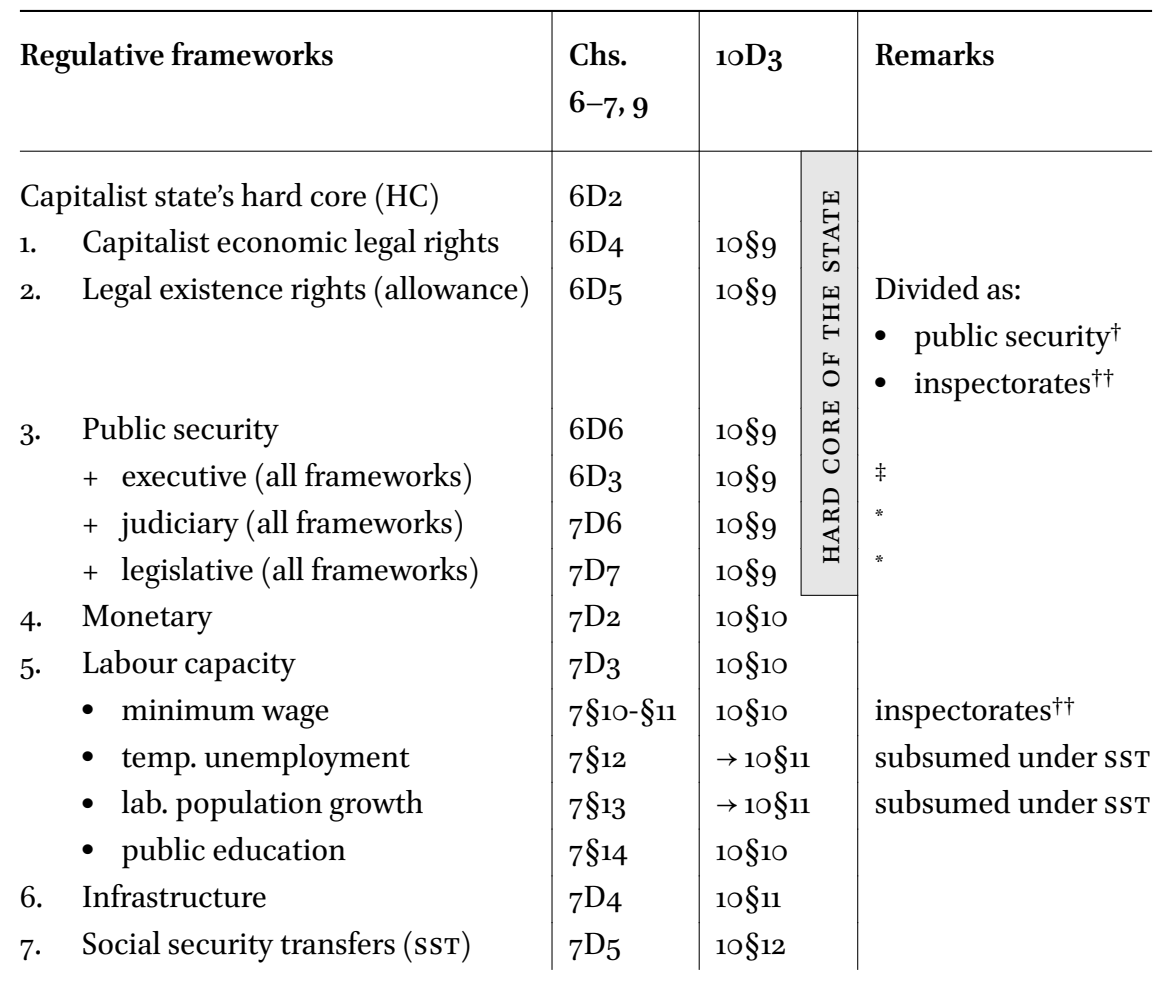


TABLE 10.13 The regulative frameworks (cont.)

\begin{tabular}{l|l|l|l}
\hline Regulative frameworks & $\begin{array}{l}\text { Chs. } \\
6-7,9\end{array}$ & $10 D_{3}$ & Remarks \\
\hline $8 . \quad$ Competition & $9 \mathrm{D} 1$ & $10 \S 13$ & \\
\hline Regulation and regulative failures & & $10 \S 13$ & \\
\hline
\end{tabular}

$\dagger \quad$ Component of forbearance of direct violence regarding the person: under public security. Components of protection of the consumer (products), of the environment, and of labour during production: under 'inspectorates'.

†† One single figure for all inspectorates.

$\ddagger \quad$ In $6 D_{3}$ (prior to the presentation of the legislative and the judiciary in Ch. 7) it is implicit that the state in general encompasses the state as 'executive'.

* $\quad$ Subsumed under hard core (for details see this Appendix 10.A, the text around Graph 10.9a).

\section{Re $10 \$ 9$ State expenditure on the Hard Core: general remarks}

Hard Core expenditure: granted rights to property, employment of labour and appropriation of surplus-value. For an estimate of the Hard Core expenditure 1870-2015, I make pragmatic use of the detailed data that we have for the period $1995^{-2015}$ and project these on the full period as a 'reference figure'. For the hard core expenditures (except one category amplified on below) this is $3.3 \%$ of GDP. (See below for the details.)

Hard Core expenditure: granted rights of or provisions for allowance existence. Part of this is subsumed under public security and the other part under 'inspectorates' (see Table 10.13). For pragmatic reasons I take the latter together with inspectorates on minimum wages. For these inspectors together I equally use a single reference figure throughout the 1870-2015 period, in this case of $0.1 \%$ of GDP.

[Re 10§9] Expenditures on the hard core, inspectorates, military and interest

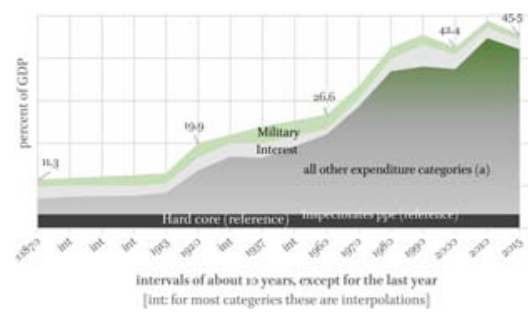
ure is a rough estimate, based on a cautious use of $1995^{-2015}$ data for leg-

The following two graphs and the surrounding information form the basis for the bottom and top of Graph 10.9 (left).

The reference figures for the Hard Core and for Inspectorates. The reference figure for the Hard Core expendit- 
islative and administrative expenditure as well as for expenditure on public order and security.

General data information: COFOG classification. The data derive from OECD 'COFOG' data (Classification of the Functions of Government). In this classification government expenditures are categorised in ten 'functions' ('first digit'). The first digit information has been used for 'Public security expenditure'. This regards COFOG category o3 (Public order and safety). For a (further) limited number of countries a subdivision is available ('second digit'), which has been used for 'Legislative and executive expenditure'. This regards COFOG category O1.01 ('Executive and legislative organs'). See also the manual COFOG, Eurostat (2011); its Appendix (pp. 155-81) sets out the COFOG structure.

Graph 10.9-a shows for these two categories the data available. For legislative and administrative expenditure these regard 9-16 countries, and for public security expenditure 16-19 countries.

GRAPH 10.9-A Hard core expenditures 1995-2015, averages of 9-19 OECD21 countries

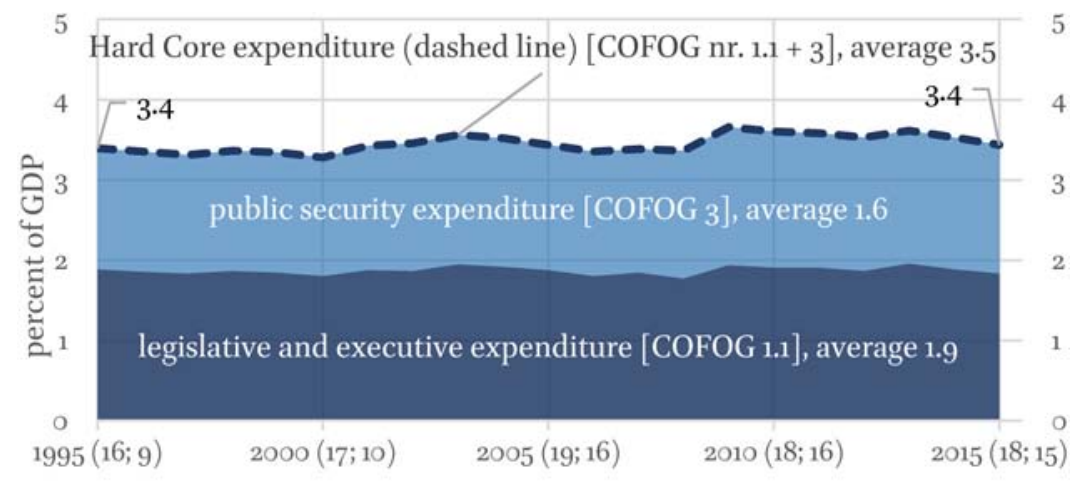

(in brackets the number of countries of the two bottom series)

DATA SOURCE: Public security (OECD dataset, National Accounts at glance - general government, expenditure by function; accessed 25 January 2018); ${ }^{60}$ Legislative and executive (OECD dataset, National Accounts, 11. Government expenditure by function (COFOG); accessed 25January 2018$)^{61}$

6o http://stats.oecd.org/OECDStat_Metadata/ShowMetadata.ashx?Dataset=NAAG\& ShowOnWeb=true\&Lang=en.

61 http://stats.oecd.org/OECDStat_Metadata/ShowMetadata.ashx?Dataset=SNA_TABLEn\&\& ShowOnWeb=true\&Lang=en. 
It can be seen from Graph 10.9- $a$ that the averages of the data available are hardly fluctuating for these years (taking into account the recession years of the early 2000 s and of about 2008-13). The data available (early 2018) are geographically biased to European countries (public security OECD-21 minus Canada and New Zealand, legislative and executive OECD-21 minus Australia, Canada, New Zealand, Switzerland and the USA).

As a rough estimate for the reference figure for the full 1870-2015 period I adopt a Hard Core expenditure of $3.3 \%$ of GDP. This means that I classify expenditure above $3.3 \%$ as contingent (appearing in my category 'other expenditure' - see this Appendix under 10§13).

The reference figure for inspectorates concerning production processes, products and the environment. In principle these expenditures are classified under COFOG category 4: Economic affairs. However, for this specific category there are no data available. The reference figure of $0.1 \%$ of GDP (main text) is a rough estimate based on expenditures for these inspectorates for the Netherlands around 2010. These regard mainly inspectorates for labour safety, of food and consumer safety, of environmental health, of fire prevention and protection from floods, and of construction. As indicated in the main text of $10 \$ 10$, all these are mainly a matter of expenditure on civil servants' wages. (That main text also indicates why financial supervision is not included in the $0.1 \%$ number.)

The upshot is that - as with Hard Core expenditure above $3.3 \%$ - I classify expenditure above $0.1 \%$ as contingent (appearing in my category 'other expenditure' - see this Appendix under 10§13).

\section{Re 10\$9 Graph 10.9: Military expenditure}

It can be seen from Graph 10.9-b that from 1950 the averages of the different sets of countries converge. In 2015 the military expenditure as a percentage of GDP approaches the 1870 level.

Data for 1870-1937 are mainly from Sabaté (2013), Figures 7-12. Added to these are data for various years from 1900 to 1937 from Tanzi and Schuknecht (2000, Table II.3) concerning Austria, Australia, Belgium, Ireland, Japan and New Zealand. 
GRAPH 10.9-B Military expenditure 1870-2015, average of up to 21 current oECD countries

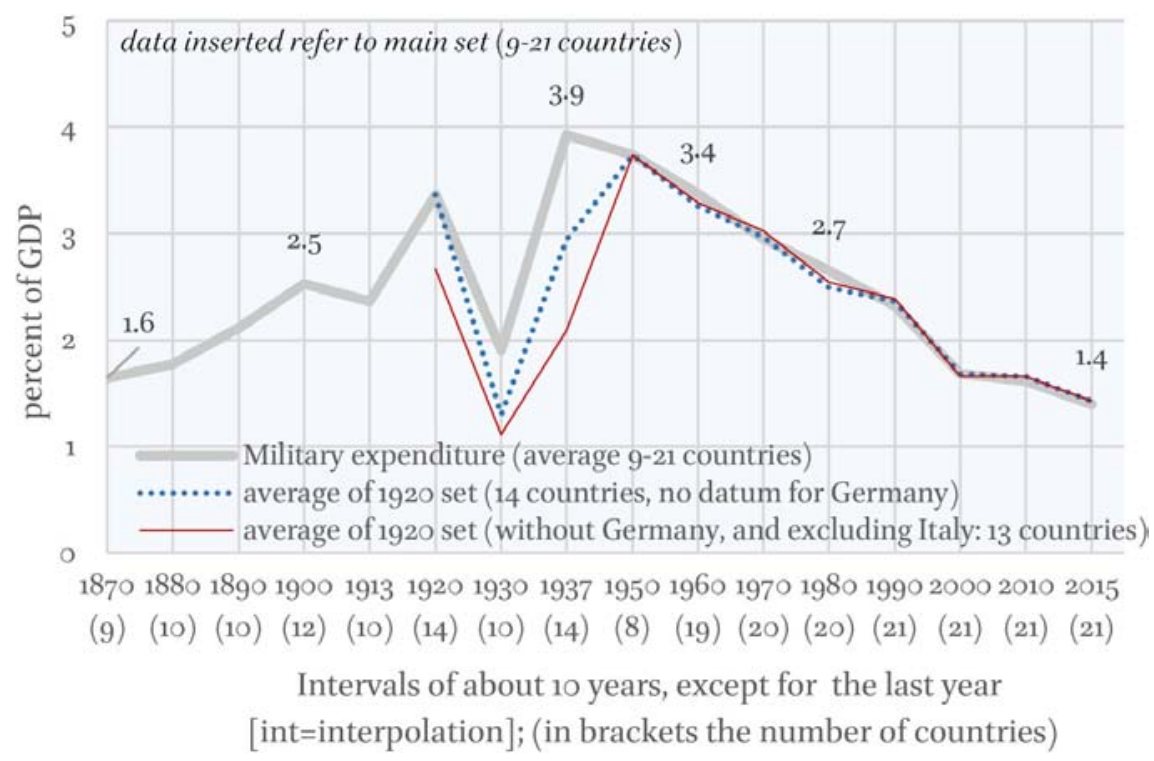

DATA SOURCES: for 1870-1937 (Sabaté 2013 with additions from Tanzi and Schuknecht 2000). For 1960-2015 (World Bank database, World Development Indicators, updated 19 January 2018, extracted 23 January 2018)

\section{Re 10 \$ Graph 10.9: Interest expenditure}

The data from before 1970 are rather scarce. Tanzi and Schuknecht provide data for 7-8 countries for 1870 and 1913, and for 13-16 countries for 1920 and 1937. Some of these data are for central government only (the data for Australia, Canada, UK and USA are for general government).

The OECD data from 1960 are for 'gross government interest payments, value', divided by GDP (Spain 196o=1964; Switzerland 196o=1965; Denmark 1970=1971; Germany $1990=1991)$. To the OECD data for 1970 and 1980 I have added the data for Australia, Germany, Ireland and the Netherlands from Tanzi and Schuknecht (they provide no data for 1960). 
GRAPH 10.9-C Gross interest expenditure 1870-2015, average of up to 21 current oECD countries

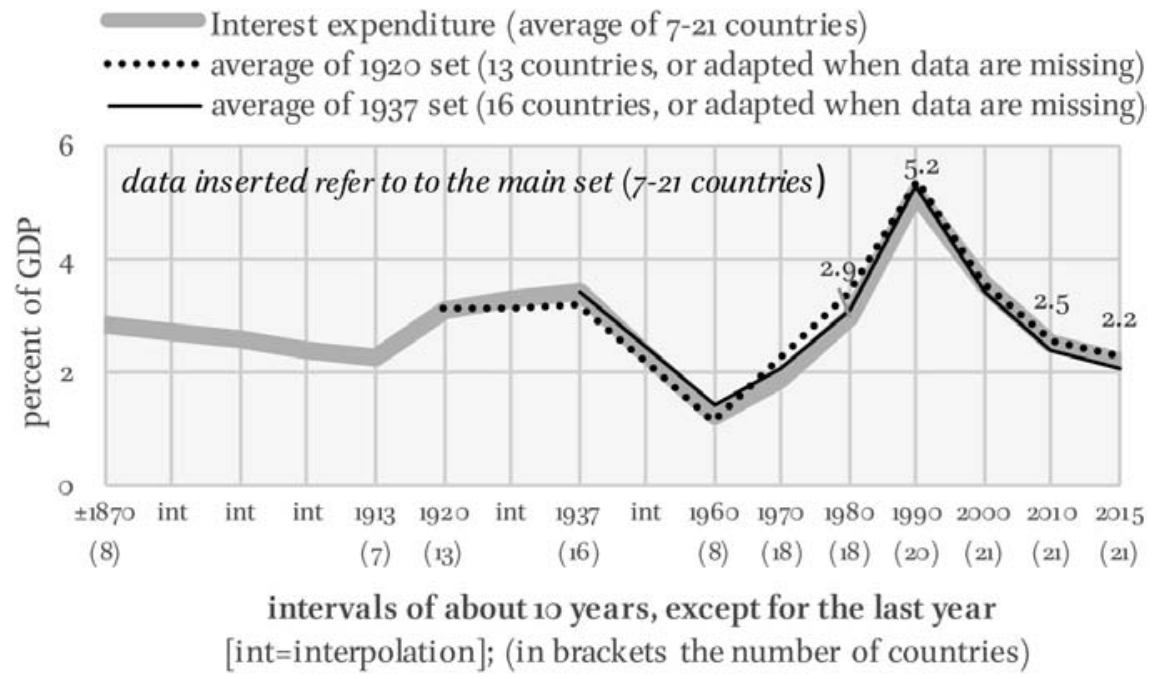

DATA SOURCES: 1870-1937 (Tanzi and Schuknecht 200o); 196o-current (OECD Economic Outlook database, November 2017, extracted 13 January 2018)

\section{Re 10 \$12 Social security transfers 1880-2015}

The available data for this category go back to only 188 o, not 1870 .

Chapter 7 distinguished between the social security transfers that are necessary as regulation of labour capacity $(7 \S 12-7 \S 13)$, and the 'generalised' transfers that may be necessary for the state's legitimation - and hence for the capitalist system. (See the summarising Figure 7.13.) Unfortunately the statistical data - and especially long-term historical data - are insufficiently applicable to this distinction. In $10 \S 12$, therefore, I take the 'temporary unemployment transfers' together with the other social transfers. In 2015 the major transfers regard public pensions, health (cure and care), and transfers to the workingage unemployed (broadly including disablement). However, only from about 1980 does the available statistic (internationally common based) allow for a distinction between these (see Graph 7.9). In Graph 10.11, therefore, I show data for the sum of the average 'OECD-defined' state expenditure on social security transfers. 


\section{[Re 10§13] 'Other expenditure' 1995-2015}



The following information regards Graph 10.12 here reproduced in reduced form (Total state expenditure (general government) and state expenditure on 'general amenities' and on 'subsidies and other direct assistance for enterprises,' 1870-2015, in \% of GDP; averages of up to 21 current OECD countries). That graph shows, from 1990 (in fact 1995), a subdivision of the category 'other expenditure'.

OECD total expenditure data from $1995^{-2015}$ are available of 21 countries. OECD expenditure data at COFOG digit 1 level are available of $16-18$ countries (and at digit 2 level of 9-16 countries) (COFOG: Classification of the Functions of Government). ${ }^{62}$

Graph 10.12- $a$ shows the statistical difference of the total expenditure of the 21 and the 16-18 countries (top of graph). This graph also shows the average expenditure of the digit 2 level 9-16 'COFOG countries' on General amenities and on Subsidies and other direct assistance for enterprises.

It can be seen that at the COFOG first digit level, the statistical difference with the total non-COFOG data for 21 countries is for some years rather large. This may also apply for the second digit level (bottom categories). In Graph 10.12 of the main text I therefore applied from 1990 the proportions of the two specifications (shown at the bottom of 10.23-a) to the category of 'other expenditures' of the dataset of 21 countries. ${ }^{63}$ See rubric D of Table 10.14.

- The category of 'direct subsidies' within the category of 'subsidies and other direct assistance for enterprises'. Subsidies to enterprises, and especially in international comparison, are (perhaps surprisingly) a rather unexplored terrain. ${ }^{64}$ Internationally comparable data can be traced back to 1960 , as shown in Graph 10.12-b. Subsidies are defined as transfers to enterprises, including public corporations, and are exclusive of loans and loan guarantees.

62 This applies for when I consulted this database in January 2018. The countries for which COFOG data are available at the first digit level are the OECD-21 minus Canada and New Zealand. On top of these, second digit level data are also lacking for Australia, Switzerland and the USA.

63 This includes COFOG category o6, housing and community amenities.

64 In a 2010 OECD paper, Spector writes that the delineations of state aid are 'based on heterogeneous definitions', and that 'the most comprehensive data about state aids are those covering the European Union' and that 'data about non-EU countries are less available and usually lack homogeneity' (Spector 2010, pp. 18-19). 
GRAPH 10.12-A Expenditure on general amenities and on subsidies and other direct assistance for enterprises (COFOG data) and statistical difference between the COFOG and total dataset, 1995-2015, various $O E C D$-21 averages

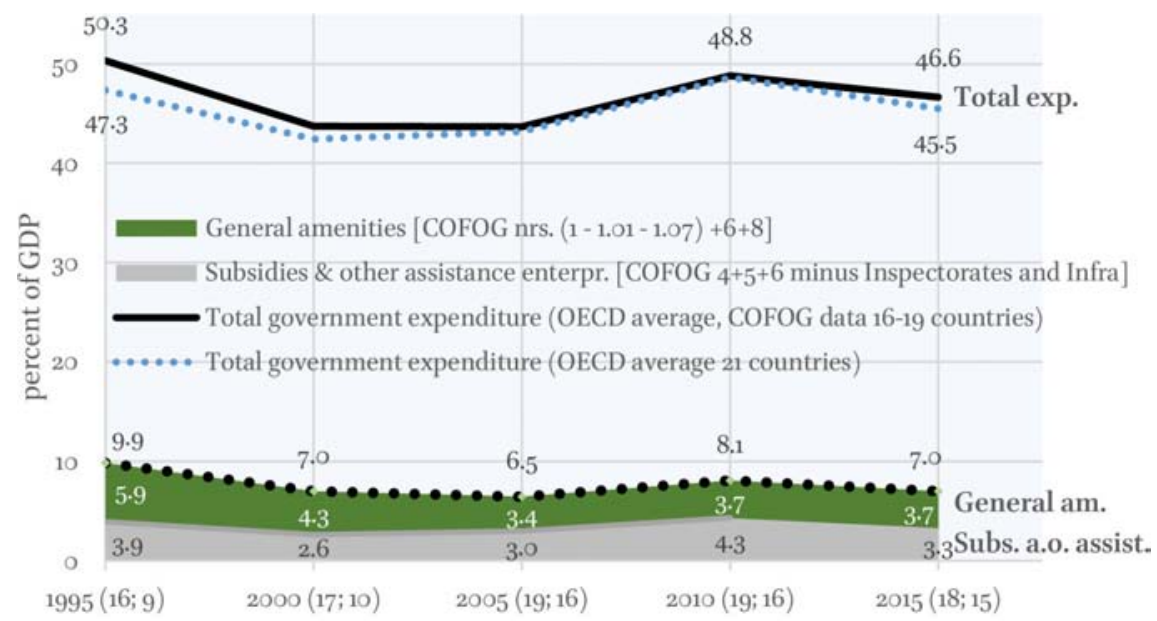

(in bracketst the number of countries: first one for total expenditure, top solid line; second one for bottom categories)

DATA SOURCES: (1) Total expenditure 21 countries, see Graph 8.2; (2) Total expenditure, COFOG data, OECD dataset National accounts at glance - general government, expenditure by function (accessed 25January 2018); 65 (3) Bottom categories, OECD dataset National Accounts, 11. Government expenditure by function (COFOG) (accessed 25January 2018) ${ }^{66}$ - see Table 10.6 for further specification of my categorisation of the data

Quantitatively this category is not a minor one. At the beginning of the twentyfirst century this was more important, in terms of its size, an expenditure category than infrastructure (average OECD-21). It can be seen from Graph 10.12- $b$ that in 2010 the average direct expenditure on subsidies was back to the 1960 level in percentage of GDP. It is very difficult to judge to what extent their downturn after 1981 has been substituted indirectly by tax subsidies (tax deductions). ${ }^{67}$ In international comparison these tax subsidies (for example, $R \& D$ related ones) are an even more unexplored terrain.

65 http://stats.oecd.org/OECDStat_Metadata/ShowMetadata.ashx?Dataset=NAAG\& ShowOnWeb=true\&Lang=en.

66 http://stats.oecd.org/OECDStat_Metadata/ShowMetadata.ashx?Dataset=SNA_TABLE11\& ShowOnWeb=true\&Lang=en.

67 From my practice as a senator in the parliament of the Netherlands (2007-15) I know that such deals are made with enterprises' organisations. 
GRAPH 10.12-B State expenditure (general government) on explicit direct subsidies for enterprises, 1960-2010, in \% of GDP; average of up to 20 OECD-21 countries ${ }^{\dagger}$

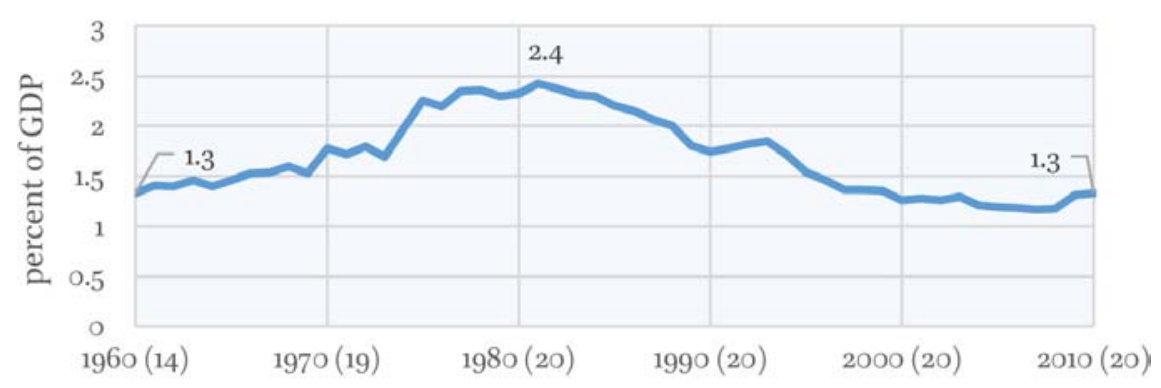

(in brackets the number of countries)

$\dagger \quad$ OECD-21 minus Switzerland. Data source: DICE Database (2013). ${ }^{68}$ (Canada and New Zealand 196o=1961; Denmark 1970=1971)

Reconsidering the main Graph 10.12 it can be seen that from 1960 the category of 'Other expenditure' increases considerably. From Graph 10.12-b it can be inferred that the $1960-81$ increase in subsidies was a major component of this.

Graph 10.12-c shows for 1995-2015 the expenditure on 'subsidies and other direct assistance for enterprises' together with its share of the direct subsidies.

GRAPH 10.12-C State expenditure (general government) on subsidies and other direct assistance for enterprises, and on competition policy, 1995-2015, in \% of GDP; average of 16-19 OECD-21 countries

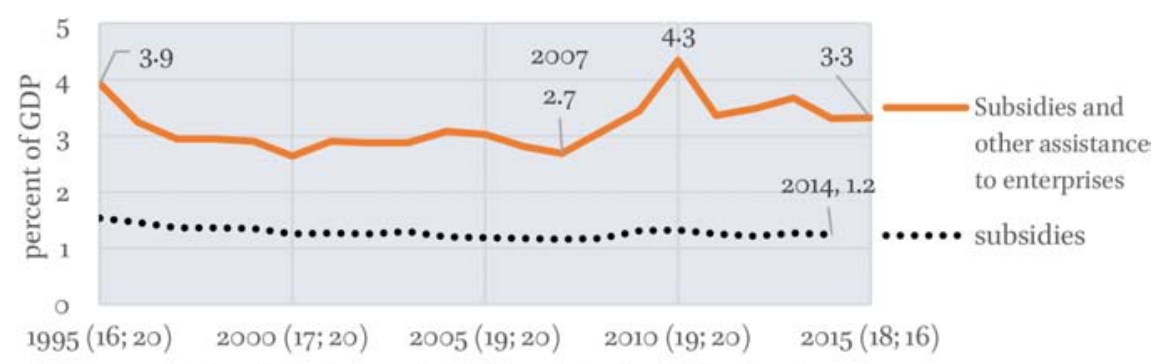

(in brackets the number of countries for each series)

DATA SourCes: Subsidies and other assistance (OECD, COFOG data, OECD dataset National Accounts at a glance - general government, expenditure by function, accessed 25 January 2018 category 4, minus expenditure on Infrastructure and on Supervision (inspectorates) of production). Subsidies: see Graph 10.12-b (with projections by DICE for 2012-14)

68 General Government Outlays by Economic Category: Subsidies as a Percentage of GDP, 196o-2014, Ifo Institute, Munich, http://www.cesifo-group.de/DICE/fb/3FRjkpsh8 (accessed 27 January 2018). 
'Other direct assistance' includes aid for particular sectors and especially also loans to enterprises. In the three years between 2007 and 2010 this rises by 1.6 points of GDP, which is due to assistance to the financial sector ('too big to fail') and to crisis-related assistance to other sectors. ${ }^{69}$ (Note that this state aid far from reflects the total of the social-economic costs of the early twenty-first century financial crisis, which has been estimated at $100 \%$ of GDP and over see Chapter 9, Appendix 9A, section 9A-3.)

\section{Re ${ }_{10 D}$ Connection between the categories adopted in ${ }_{10 D}$ and the coFoG categories}

See Table 10.14. The major purpose of this table is to show how the categories adopted in ${ }_{10 D}$ are connected to the COFOG categories (table rubrics A-C). Recall from the clarification General data information: COFOG classification in this Appendix under $10 \S 9$ that the first digit classification of COFOG is one in ten categories.

TABLE 10.14 Connection between the categories adopted in $10 D_{3}$ and the COFOG categories (table rubrics $A-C$ ); and the proportions of General amenities and Additional amenities for enterprises in the COFOG based 'Other Expenditures' (table rubric D)

$\begin{array}{ll}2015 & \text { classification Categories Ch. } 10^{\dagger} \\ \text { \% GDP } & \text { COFOG } \\ \text { example } & \end{array}$

A COFOG categories

1 General public service

1a legislative and executive

${ }_{1 b}$ debt transactions (mainly interest) ${ }^{\ddagger}$

$1 c$ other public services of COFOG 1 ( row 1 minus 1 a and 16 )

2 Defence

3 Public security

4 Economic affairs

Environment protection (infrastructural)

6 Housing and community amenities

Health

8 Recreation, culture, religion

$\begin{array}{ll}6.4 & 1 \\ 1.8 & 1.1 \\ 2.3 & 1.7 \\ 2.2 & \\ 1.3 & 2 \\ 1.6 & 3 \\ 4.6 & 4 \\ 0.7 & 5 \\ 0.5 & 6 \\ 7.0 & 7 \\ 1.0 & 8\end{array}$

69 Spector indicates that EU data show 'that in spite of a strict control over state aids, their total amount, excluding measures related to the financial crisis, was still $€ 113.4$ billion in 2008, or $0.94 \%$ of EU GDP. Not taking aid to railways into account, the volume of aid has been halved between 1992 and 2008, from $1 \%$ to $0.54 \%$. The inclusion of crisis measures 
TABLE 10.14 Connection between the categories (cont.)

\begin{tabular}{|c|c|c|c|c|}
\hline & & $\begin{array}{l}2015 \\
\% \text { GDP } \\
\text { example }\end{array}$ & $\begin{array}{l}\text { classification } \\
\text { COFOG }\end{array}$ & Categories Ch. $10^{\dagger}$ \\
\hline 9 & Education & 5.2 & 9 & \\
\hline 10 & Social protection & 18.3 & 10 & \\
\hline 11 & $\begin{array}{l}\text { Total expenditure: OECD average, COFOG data } 18 \\
\text { countries (2O15) (row } 1 \text { to } 10 \text { ) }\end{array}$ & 46.6 & $=1$ to 10 & \\
\hline 12 & Total expenditure: OECD average 21 countries (2015) & $45 \cdot 5$ & & \\
\hline 13 & Statistical difference (row 12-11) & -1.1 & & \\
\hline B & Regrouped COFOG categories & & & \\
\hline 14 & Defence (row 2) & 1.3 & 2 & Military \\
\hline 15 & Debt transactions (mainly interest) (row $1 \mathrm{~b}$ ) & 2.3 & 1.7 & Interest \\
\hline 16 & Legislative plus public security (row 1a plus 3 ) & $3 \cdot 4$ & $1.1+3$ & Hard Core \\
\hline 17 & $\begin{array}{l}\text { General services, foreign aid, culture, recreation, } \\
\text { community (row ic plus } 6 \text { and } 8 \text { ) }\end{array}$ & $3 \cdot 7$ & $\begin{array}{l}1-(1.1+1.7)+ \\
6+8\end{array}$ & General amenities \\
\hline 18 & $\begin{array}{l}\text { Infrastructure plus Inspectorates plus subsidies and } \\
\text { other assistance to enterprises and competition policy } \\
\text { (row } 4 \text { plus 5) }\end{array}$ & $5 \cdot 3$ & $4+5$ & \\
\hline 19 & Education & 5.2 & 9 & Education \\
\hline 20 & Social security & $25 \cdot 3$ & $7+10$ & Social security \\
\hline 21 & $\begin{array}{l}\text { Total expenditure, OECD average COFOG data } \\
\text { (row } 14 \text { to 2O) }\end{array}$ & 46.6 & $=1$ to 10 & \\
\hline $\mathrm{C}$ & Other categories Ch. 10 & & & \\
\hline 22 & $\begin{array}{l}\text { Inspectorates production, product and environment } \\
\text { (reference figure) }\end{array}$ & 0.1 & & Inspectorates \\
\hline 23 & Infrastructure indicator $(57.5 \%$ gross investment $)$ & 1.9 & & Infrastructure \\
\hline 24 & $\begin{array}{l}\text { Subsidies and other economic policy amenities for } \\
\text { enterprises (row } 18 \text { minus } 22 \text { and } 23 \text { ) }\end{array}$ & $3 \cdot 3$ & & $\begin{array}{l}\text { Additional } \\
\text { amenities for } \\
\text { enterprises }\end{array}$ \\
\hline 25 & sum of other categories (row 22 to $24=$ row 18 ) & $5 \cdot 3$ & & \\
\hline
\end{tabular}

changes the picture dramatically, since they amounted to $€ 212.2$ billion, or $1.7 \%$ of GDP.' And: 'Aid to agriculture in OECD countries alone amounted to $\$ 318$ billion in 2002' (Spector 2010, pp. 18-19). 
TABLE 10.14 Connection between the categories (cont.)

$\begin{array}{ll}2015 & \text { classification Categories Ch. } 10^{\dagger} \\ \text { \% GDP } & \text { COFOG } \\ \text { example } & \end{array}$

D Estimate of General amenities and Subsidies and other economic policy amenities for the total of $20-21$ countries (accounting for statistical differences) ${ }^{*}$

26 'Other expenditures' (average of 21 countries) 6.8

27 'Other expenditures' (COFOG average) row 17 plus 24

7.0

Proportion of General amenities in Other expenditures COFOG (row 17 / row 27)

29 Proportion of Subsidies etc. in Other expenditures COFOG (row 24 / row 27)

30 General amenities: estimate for 21 countries (row 26 * row 28 )

31 Subsidies a.o. economic policy amenities: estimate for $21 \quad 3.2$ countries (row $26 *$ row 29)

$\dagger$ The 2015 data listed in the third column may slightly deviate from the data provided in various graphs because the former data for 2015 are the average of 19 countries and the latter of 21 countries.

‡ Data for these two Cofog level 2 categories are available for 9-10 countries for $1995^{-2000}$ and for $15^{-16}$ countries onwards.

* Note that proportions of rows 28-29 (and hence those of rows 30-31) are not constants, but different for each single year (as can be seen from the bottom figures of Graph 10.12-b).

DATA SOURCE RUBRIC A: OECD, Datasets: National Accounts at a glance, and Government expenditure by function $(\mathrm{COFOG})^{70}$

\section{List of figures chapter 10}

\section{Scheme $10.1 \quad$ The reach of the capitalist state (outline Chapter 10) 470}

10§1. The size of the state: state expenditure as mitigating economic recessions Graph $10.2 \quad$ Growth amplitudes as measured by the growth rate of real-GDP per capita, USA 1870-2015 in 2011 prices 473

70 http://stats.oecd.org/. Rows 1a and 1b: Dataset: 11, Government expenditure by function (COFOG), http://stats.oecd.org/index.aspx?DatasetCode=SNA_TABLE11. 
10§2. State policy in recessions versus depressions

Graph 10.3 Average number of recessions per decade and per country 1870-2008, for a sample of current OECD countries 476

10\$4. A conceptual outline of the reach of regulation

Figure 10.4 Conceptual outline of the reach of regulation 480

10\$5. Quantity and density of regulation: (too) simple measures

Graph $10.5 \quad$ Number of laws in force, the Netherlands 1980-2015 (central government, exclusive delegated and EU regulation) 483

Graph $10.6 \quad$ Number of total delegated regulations issued each year, and cumulative total of the delegated general regulations without expiry date; European Union 1967-2012 485

Graph 10.7 Development of the quantity of delegated regulation in force at the federal state level in the US: total number of pages 1950-2015 486

10§6. Complexity of regulation: the combination of complication, interweaving and field fusion

Graph 10.8 Visualisation of the interweaving of the UK 'Companies, Audit, Investigations and Community Enterprise Act 2004' with other earlier and later Acts. 490

10§9. The necessary state expenditure on the Hard Core and Inspectorates, and the contingent military and interest expenditure

Graph 10.9 Total state expenditure (general government) and expenditure on the Hard Core, as well as on contingent military and interest expenditure, 1870-2015, in \% of GDP; averages of up to 21 current OECD countries 496

10§11. Expenditure on the infrastructural framework

Graph $10.10 \quad$ Total state expenditure (general government) and the expenditure on education and infrastructure, 1870-2015, in \% of GDP; averages of up to 21 current OECD countries 498

10§12. Expenditure on social security as connected with the development of the accumulation of capital

Graph 10.11 Total state expenditure (general government) and state expenditure on social security, 1870-2015, in \% of GDP; averages of up to 21 current oECD countries 501 
10§13. 'Other state expenditure': contingent expenditure and required expenditure on especially 'too big to fail' banks

Graph 10.12 Total state expenditure (general government) and state expenditure on 'general amenities' and on 'subsidies and other direct assistance for enterprises, $1870-2015$, in \% of GDP; averages of up to 21 current $O E C D$ countries $5 \mathrm{O} 3$

Appendix 10.A. Data and data sources of the graphs in Chapter 10

Table 10.13 The regulative frameworks and empirical-statistical expenditure categories for Division $3 \quad 509$

Graph 10.9-a Hard core expenditures 1995-2015, averages of 9-19 OECD-21 countries 511

Graph 10.9-b Military expenditure 1870-2015, average of up to 21 current OECD countries 513

Graph 10.9-c Gross interest expenditure 1870-2015, average of up to 21 current OECD countries 514

Graph 10.12-a Expenditure on general amenities and on subsidies and other direct assistance for enterprises (COFOG data) and statistical difference between the COFOG and total dataset, 1995-2015, various OECD-21 averages 516

Graph 10.12-b State expenditure (general government) on explicit direct subsidies for enterprises, 1960-2010, in \% of GDP; average of up to 20 OECD-21 countries 517

Graph 10.12-c State expenditure (general government) on subsidies and other direct assistance for enterprises, and on competition policy, 1995-2015, in \% of GDP; average of 16-19 OECD-21 countries 517

Table 10.14 Connection between the categories adopted in $10 D_{3}$ and the COFOG categories; and the proportions of General amenities and Additional amenities for enterprises in the COFOG based 'Other Expenditures' 518 